\title{
Sound-Localization Deficits Induced by Lesions in the Barn Owl's Auditory Space Map
}

\author{
Hermann Wagner \\ Max-Planck-Institut für biologische Kybernetik, D-7400 Tübingen, Germany
}

Barn owls possess a two-dimensional map of auditory space. The map appears in its final form in the external nucleus of the inferior colliculus (ICX) and is projected from there to the optic tectum (OT). To determine the role of the map in ICx or its projected version in OT in the localization of acoustic stimuli, head movements of three adult owls were recorded before and after lesioning parts of the map either in ICx or in OT. Small electrolytic lesions caused sound-localization deficits that were characterized by failures to turn, turns away from the sound source, increased response latencies, and reduced turning amplitudes. These deficits occurred at azimuths expected from the physiological data obtained at the lesion site before passing current. They extended over an azimuthal range of some $20^{\circ}$. Thus, this is the first unambiguous demonstration, for sound localization, of a deficit covering a well circumscribed area within an auditory hemifield. Since the major lesion deficits were restricted to one hemifield, a second lesion was made in the space map of the other side of the brain in each animal. The second lesion resulted in behavioral deficits qualitatively similar to those produced by the first lesion. In total, the study is based on nine lesions, three in each owl. Two lesions were sham lesions. These and two further lesions did not produce a measurable deficit. In four of the five remaining cases, in which a behavioral deficit was observed initially, the behavioral performance recovered with time. In two cases, the deficit disappeared completely. Although improvement occurred also in the remaining two cases, prelesion response amplitudes were not reached in one case, and response latency did not reach prelesion values in the other case. Because the behavioral deficits induced by the second lesions disappeared in the same way as did the deficits induced by the first lesions, the possibility is excluded that the animals learned to respond tactically, that is, that they learned to associate "unlocatable sounds" with the lesioned side. The deficits were also not due to a generalized motor impairment,

Received Dec. 18, 1991; revised July 21, 1992; accepted July 27, 1992.

This work could not have been performed without the expert help of Henning Blanke, Mark von Campenhausen, Albrecht Müller, and Guido Reetz, who all did not hesitate to work long night hours. Ina Pappe, Gisela Schubert, and Dagmar Teuchert helped with histology and produced excellent drawings. John Power built the electronics of the head-coil system, Herb Adams built the hoop, and the people in the workshops of the Max-Planck-Institut installed the setup. Onur Güntürkün, Dirk Kautz, Mark Konishi, Christian Müller, Terry Takahashi, and Susan Volman read an earlier version of the manuscript and provided many useful comments and criticisms. Susan Volman also helped with the English. This research was supported by the Deutsche Forschungsgemeinschaft (SFB 307).

Correspondence should be addressed to Dr. Hermann Wagner, Max-PlanckInstitut für biologische Kybernetik, Spemannstrasse 38, D-7400 Tübingen, Germany.

Copyright (c) 1993 Society for Neuroscience $0270-6474 / 93 / 130371-16 \$ 05.00 / 0$ because immediately after the lesion the animals responded as they did before the lesion to stimulation from outside the well circumscribed affected region of space. The possibility is discussed that plasticity after small central (neural) injuries is maintained longer in the lifetime of an animal than plasticity after peripheral (mechanical) manipulations.

IKey words: interaural time difference, recovery, inferior colliculus, optic tectum, plasticity, sensory deficit]

Since the original discovery by Knudsen and Konishi (1978a) of an auditory space map in the owl, similar findings have been reported in other species (King and Palmer, 1983; Middlebrooks and Knudsen, 1984; Pollack et al., 1986; King and Hutchings, 1987; Withington-Wray et al., 1990).

The present article addresses two issues concerning auditory space maps. First, the significance of auditory space maps in sound-localization behavior has been questioned (Jenkins and Merzenich, 1984; Merzenich et al., 1984), because auditory information is processed in parallel pathways in the brain. While the space maps have been detected in the midbrain, most notably in the superior colliculus or in its avian homolog, the optic tectum (OT), behavioral experiments with higher mammals have shown that the auditory cortex (the avian analog being field $\mathrm{L}$ ) is essential for sound localization (since I present experiments on owls, I shall use the avian terms from here on). The OT and field $\mathrm{L}$ are innervated by two independent pathways. In the owl, both pathways originate in the central nucleus of the inferior colliculus (ICc). One pathway leads via the external nucleus of the inferior colliculus (ICx) and OT to the motor centers and is therefore termed the "ICc-ICx-OT" pathway. The other pathway originating in ICc includes the thalamic nucleus ovoidalis (Ov) and the auditory forebrain (field L), and is termed the "ICCOv-L" pathway. No interconnection between these pathways is known.

The second issue to be addressed is the question of place coding of sound location. The space maps are composed of neurons that have spatially restricted receptive fields, the spacespecific neurons. In the owl, space-specific neurons occur in nuclei of both pathways mentioned above, but a systematic arrangement of the neurons according to the spatial coordinates of their receptive fields, that is, a map of auditory space, has been discovered in the ICc-ICx-OT pathway only (Knudsen et al., 1977; Knudsen and Konishi, 1978a,b). The existence of a map suggests that sensory space is represented by place in the brain, but this has not been tested behaviorally.

Thus, the specific questions to be asked are whether a lesion in the space map causes a deficit in the owl's sound-localization performance at all and, if so, whether the deficit is restricted to that spatial area that is represented by the lesioned area in the 
map ("local deficit") or whether a lesion leads to a behavioral deficit extending over large regions of auditory space ("global deficit"). Since sound azimuth is more finely mapped than elevation, this study focuses on the effects of lesions on azimuthal localization. The results presented below demonstrate that a lesion causes a local deficit in sound localization.

\section{Materials and Methods}

Three captive-bred, adult barn owls (Tyto alba) were used in the experiments, and the initials of the owls' names $(C, M, P)$ will be used for identification. When they received the first lesion, the owls were all older than 15 months. Each animal received three lesions. Two lesions were sham lesions: the second lesion in owl $\mathrm{C}(\mathrm{C} 2)$ and the third lesion in owl $\mathrm{P}(\mathrm{P} 3)$. Thus, the results concerning the specific lesion effects are based on seven lesions, two each in animal $\mathrm{C}(\mathrm{C1}, \mathrm{C} 3)$ and animal $\mathrm{P}$ (P1, P2), and three in animal M (M1, M2, M3). Standard extracellular electrophysiological techniques were used to record single- and multiunit activity before lesioning. The behavioral procedures were similar to those described earlier (Knudsen et al., 1979; Moiseff and Konishi, 1981; Wagner, 1991).

Surgery and animal care. All experiments including either surgery or clectrophysiological recordings were performed under anesthesia (ketamine, $20 \mathrm{mg} / \mathrm{hr} / \mathrm{kg}$ ). Diazepam (Valium; $1 \mathrm{mg} / \mathrm{hr} / \mathrm{kg}$ ) was given as a relaxant, and atropine sulfate $(0.05 \mathrm{mg} / \mathrm{kg})$ was used to prevent salivation. Surgery was performed aseptically.

At the beginning of an experiment, a stainless steel head plate was fixed to the animal's skull. For this operation, the anesthetized animal was placed in a stereotaxic head-holder that fixed the head such that the plane defined by the center of the ear bars and the ventral surface of the palatine ridge was tilted downwardly $45^{\circ}$ from the horizontal plane. Then the plate was fixed to the skull with dental cement and a reference post was glued onto the skull at the intersection of the interaural axis and the midline of the skull.

For the electrophysiological experiments, a skin incision was made over the dorsal surface of the skull, and part of the dural surface was exposed through craniotomy. A heating pad warmed the animal throughout the experiment. Glass-coated platinum-iridium electrodes were positioned with respect to the reference post and advanced through the brain from dorsal to ventral with a remote-controlled stepping motor. After placing lesions, the craniotomy and skin incision were closed, the wound was treated with an antibiotic cream, and the animal was placed in an observation cage. Experiments were kept as short as possible, and animals usually awoke within $2-3 \mathrm{hr}$ from the anesthesia. They were alert and did not show any nonspecific impairment on the day after the lesions, and no signs of discomfort were visible.

Placement of lesions. The organization of the space map is well known (for reviews, see Knudsen, 1984; Knudsen et al., 1987; Konishi et al., 1988). Azimuth is mapped from anteromedial to posterolateral, and elevation is mapped dorsoventrally. The main cue for the representation of azimuth is the interaural time difference (ITD), and the main cue for the representation of elevation is the interaural level difference (ILD) (Knudsen and Konishi, 1979; Moiseff and Konishi, 1981; Moiseff, 1989; Olsen et al., 1989). Neurons located in the auditory pathway before the ICX are narrowly tuned to frequency (Knudsen, 1984). Frequency tuning becomes broad in ICx (Knudsen, 1984). When stimulated with broadband noise, ICx neurons have only one peak in response to ITD, while their response to tones is cyclically modulated as a function of ITD (Takahashi and Konishi, 1986). The cyclic modulation of the response as a function of ITD is seen in neurons in the nuclei before ICX to stimulation with tones or with noise (Moiseff and Konishi, 1983; Wagner et al., 1987; Fujita and Konishi, 1991). ICx and OT can be discriminated, because neurons in OT, but not those in $\mathrm{ICx}$, respond to visual stimuli.

By applying these criteria, it was possible to find the space map in either ICx or OT in physiological experiments. Multiunit and singleunit recordings were obtained. The tuning to frequency, ITD, ILD, and free-field stimuli, as well as response latencies and monaural input characteristics were assessed (see also Table 2). Since frontal auditory space is represented on both sides of the brain, care was taken to move the electrode to a locus in the map that represented lateral auditory space. After a suitable site was reached, one to four electrolytic lesions (World Precision Instruments A320; $0.6-0.8 \mathrm{~mA}$ DC current pulsed with a period of $400 \mathrm{msec}$ and a duty cycle of 0.83 for $30 \mathrm{sec}$ ) were made.
Lesions were separated by intervals of $400 \mu \mathrm{m}$ in the dorsoventral axis In this way, the representation in the map of a certain azimuth over all elevations was annihilated. The experimental procedure before making the sham lesions was the same as that described above. However, sham lesions were made in the forebrain by pressure injection of ibotenic acid.

Verification of lesions by histology. At the end of an experiment, the animals were deeply anesthetized with an overdose of pentobarbital (Nembutal, $60 \mathrm{mg} / \mathrm{kg}$ ) and perfused with $4 \%$ paraformaldehyde. Brains were blocked stereotaxically and placed in $30 \%$ sucrose until they sank. Thirty-micrometer-thick frozen sections were cut on a microtome. Alternate sections were stained with cresyl violet to mark somata or Luxol fast blue (LFB; DuPont solvent blue 37) to mark fiber tracts. Camera lucida drawings were made from the sections. Since the lesions erased considerable parts of the midbrain, a standard brain, cut at the same angle, was used to reconstruct the prelesion shapes of the affected nuclei, and to estimate the extent of the lesions.

Stimuli. In the behavioral tests, birds were stimulated with broadband noise from a free-field speaker [Mac Audio, ML103E; $10 \mathrm{~cm}$ speaker, output flat ( $\pm 5 \mathrm{~dB}$ ) from 0.8 to $10 \mathrm{kHz}$ ) that was mounted on a vertically oriented hoop of $1 \mathrm{~m}$ radius. The equipment was calibrated with a Bruel\&Kjaer sound level meter (type 2235) and a Bruel\&Kjaer microphone (type 4145). The speaker could be moved along the hoop and the hoop could be rotated about its vertical axis so that the speaker could be positioned almost anywhere in the frontal auditory field. Before a trial, the speaker was moved in a random fashion to 1 of 12 predetermined azimuthal positions at zero elevation. Although the owls could hear the stepping motor driving the hoop, they did not pay attention to these movements, and control experiments with an array of stationary speakers and also with earphones did not show differences in the owls' responses. Test stimuli were bursts of broad-band noise with a duration of either $50 \mathrm{msec}$ or $100 \mathrm{msec}$ and rise/fall times of $5 \mathrm{msec}$, which were generated with a Wavetek model 132 signal generator and a custombuilt electronic switch and were amplified with a power amplifier (Yamaha AX-300). No difference in the owls' responses to the two test stimuli could be detected. The range of sound levels was from -15 to $+30 \mathrm{~dB}$ sound pressure level (SPL) or about $0-45 \mathrm{~dB}$ above the owl's hearing threshold. For the tests reported in Figures 1-7, the sound level was $30 \mathrm{~dB}$ above the hearing threshold of owl $\mathrm{C}$ and $10 \mathrm{~dB}$ above the hearing threshold of owls $M$ and $P$. To test for an animal's alertness, in some cases a centering stimulus (click) was presented from a speaker $1.5 \mathrm{~m}$ in front of the animal before the test stimulus was triggered. The dichotic stimulus used in the electrophysiological recordings was of 100 msec duration and had $5 \mathrm{msec}$ rise/fall times. It was presented to the owl via stereo earphones (Sony MDR-E 272). Testing for ITD sensitivity covered a range of $\pm 300 \mu \mathrm{sec}$ in $30 \mu \mathrm{sec}$ steps, while testing for ILD sensitivity ranged from $-30 \mathrm{~dB}$ to $+30 \mathrm{~dB}$ in $4 \mathrm{~dB}$ steps.

Behavioral procedures. During a behavioral experiment, the birds were placed on a perch in the center of a darkened sound-attenuating chamber. The birds' head turns in response to sounds were measured with a custom-built search-coil system. Three orthogonally oriented pairs of Helmholtz coils generated rotating magnetic fields. Three small coils, mounted orthogonally to each other, were screwed to the metal plate on the animal's head during an experiment. This measurement system had an extended linear range compared to those used earlier (Knudsen et al., 1979; Moiseff and Konishi, 1981). Head positions were measured every $5 \mathrm{msec}$ for $2.5 \mathrm{sec}$ and stored in a computer (IBM AT) for off-line processing. Measurement errors did not exceed $2^{\circ}$ in the range of azimuths and elevations tested in this study. The center of the external coordinate system (zero azimuth, zero elevation) used for stimulation and recording was directly in front of the animal, where the centering speaker and an infrared-sensitive video camera were positioned. This camera and a second one $1 \mathrm{~m}$ above the owl's head allowed monitoring of the owls' general behavior. The initial head orientation, that is, the head orientation at the onset of the stimulus, was measured in the external coordinate system. Because the owls did not always look straight ahead when the stimulus was presented, the orientation-response measurements were transformed into an owl-centered coordinate system with zero azimuth in the owls' midsagittal plane and zero elevation defined by the horizontal plane containing the owls' interaural axis and the ventral surface of the palatine ridge. The azimuthal or elevational positions of the stimulus were always measured in the owlcentered coordinate system.

To maintain the owls' interest in the experiments, their weight was kept at about $85-90 \%$ of their normal weight and they had to learn to eat from a semiautomatic feeder during an initial training phase. The 
owl was rewarded with a small piece of meat from the feeder if it turned toward the test speaker after the test stimulus. During the training phase, the test stimulus was sometimes repeated if the owl did not respond the first time. During the test phase, however, the test stimulus was presented only once, and each trial was used for the statistical analyses. Trials in which the computer algorithm reported a response latency below $55 \mathrm{msec}$ were discarded, because the independently dctcrmincd shortest response latency of the owls was $55 \mathrm{msec}$. Accordingly, all turns were open-loop turns when stimulus duration was $50 \mathrm{msec}$. Since each response of the animal counted, the purpose of the training was to teach the owls to respond reliably, rather than to fixate the target accurately. Twenty to fifty data points could be obtained per day for a period of several weeks. Then testing was suspended for some time before further test blocks were conducted.

Behavioral variability. In every behavioral experiment, some variability in the performance must be expected. In the experiments reported here, this variability may result from (1) the different experimenters who participated in the study; (2) the variation in the time of day at which experiments were performed; (3) the regularity of experiments, that is, whether experiments were performed with an animal every day or more seldom; (4) the status of the animal, that is, whether it was "tired" or alert, sexually active, and so on; or (5) the weight of the animal. Although care was taken to work as systematically as possible, these sources of variability could not be totally excluded in the longterm studies. The weight played an especially important role. Variation of the weight of as low as $10 \mathrm{gm}$ might notably influence performance: if the animal was too heavy, it soon lost interest in the task, whereas if the animal was too slim, it tended to be too nervous. In addition, the owls' normal weight was found to change over a period of months. All these influences on the behavioral performance are summarized under the term "naturally occurring variability in my conditions" or, in short, "naturally occurring variability." They constitute an unexplained factor in the experiments that has to be taken into account when the results are judged. I measured the variability with a nonparametric test ( $U$ test of Wilcoxon, Mann, and Whitney) because neither the distribution of turning angle nor the distribution of response latency can be expected to be normal.

\section{Results}

Characteristics of azimuthal sound localization before lesioning

If barn owls hear a faint sound, they usually turn their head in the direction of the sound source. They may remain in a fixed position for several seconds, apparently waiting for a second sound (Payne, 1971). I accepted only those turns for the later analysis in which the owl did not turn more than $2^{\circ}$ after the centering stimulus and during the first $50 \mathrm{msec}$ after the onset of the test stimulus. This condition was fulfilled in more than $90 \%$ of the trials. In those cases in which no centering stimulus was used, the experimenter waited until the owl was approximately facing toward the centering speaker before starting the test trial. The mean and SD of the owls' head azimuth, in external coordinates, at response onset were, for owl C, 1871 trials, $2.4 \pm 7.3^{\circ}$; owl M, 2545 trials, $-2.5 \pm 9.6^{\circ}$; owl P, 1293 trials, $-0.3 \pm 9.5^{\circ}$.

For this study, the azimuthal component of hcad turning is used to characterize the owl's sound-localization behavior. The animals typically fixated the source for only a short time and then turned toward zero azimuth (Fig. 1). The reason for this was that they expected the reward at zero azimuth. Thus, only the first turn occurring after a test stimulus was analyzed.

In all three animals a linear relationship was found between the azimuthal position of the stimulus, in owl-centered coordinates, and the amplitude of the head turn. Usually, the birds undershot the sound source by variable amounts (Figs. 1, 2a,c,e; $3 a ; 4 a, c, e ; 5 a, c)$. Turns away from the sound source, that is, a turn to the left when the sound source was positioned to the right, were rarely observed. The naturally occurring variability

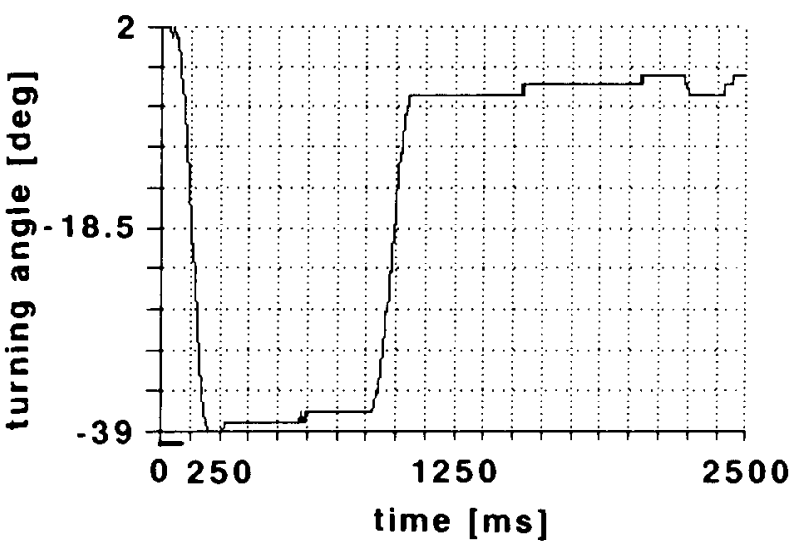

Figure 1. Azimuthal component of a head turn. After a centering stimulus at zero azimuth, a test stimulus at $-60^{\circ}$ was presented. This corresponded to $-62^{\circ}$ in the owl-centered coordinate system. Thus, the azimuthal position of the stimulus as plotted in Figures $2-5$ and 8 was $-62^{\circ}$ in this case. The owl turned with a latency of $85 \mathrm{msec}$ and a maximal velocity of -371 degrees/sec toward the source. It undershot the target, however, by $21^{\circ}$. The duration of the test stimulus is indicated by the bar below the time axis. The criterion for the start of the turn was a change in azimuth of more than $2^{\circ}$ from the resting position.

of the turning amplitude was assessed in owl $\mathrm{C}$ by comparing two data sets that were recorded sequentially before any lesion was made (Table 1, owl C, control TA). According to this control, the naturally occurring variability was quite large and extended to $p<0.05$, but not below. Thus, only probabilities of 0.01 and below can be regarded as being outside the naturally occurring variability.

Most response latencies were between $70 \mathrm{msec}$ and $300 \mathrm{msec}$ (Figs. 1, 2). Although the latencies were largely independent of azimuth in all three owls, they did tend to be more variable for stimuli from very lateral loci $\left(>70^{\circ},<-70^{\circ}\right)$ or very frontal loci $\left(-25^{\circ}\right.$ to $+25^{\circ}$ ) (Fig. $\left.2 b, d, f\right)$. Response latency varied between owls. Owl C, for example, had the longest mean latencies, and also it failed to turn most often (Fig. 2b). The variability of response latency was assessed in the same way as the variability of turning amplitude (Table 1, owl C, control D). The naturally occurring variability was quite large and extended to $p<0.001$, but not below. The lower range of response latencies found before any lesion was made was, however, similar for all birds. If only those $50 \%$ of the turns that had the shortest latencies were considered, the mean values were $87 \mathrm{msec}$ for owl $\mathrm{C}$ and 99 msec for owls $M$ and $P$.

The rectangular shape of the perch guaranteed that the owls' body was generally pointing toward the center of the external coordinate system, but the orientation of the owls' head was variable. To test whether the initial head orientation had an influence on the behavior, the data were divided into three subsets (initial head orientation $<-5^{\circ}\left[5^{\circ}\right.$ or more to the left of the center position]; initial head orientation between $-5^{\circ}$ and $+5^{\circ}$; initial head orientation $>5^{\circ}$; see Figs. $2,3,5$ ). In trials where the initial head orientation was more than $5^{\circ}$ from the center position, response latency appeared to be longer than in the trials when the head was centered (Fig. $2 b, d, f$ ), but the $U$ test did not reveal a difference between the data sets. Thus, consistent with an earlier report (Du Lac and Knudsen, 1990), neither turning amplitude nor response latency depended on the initial head orientation (Fig. 2). 

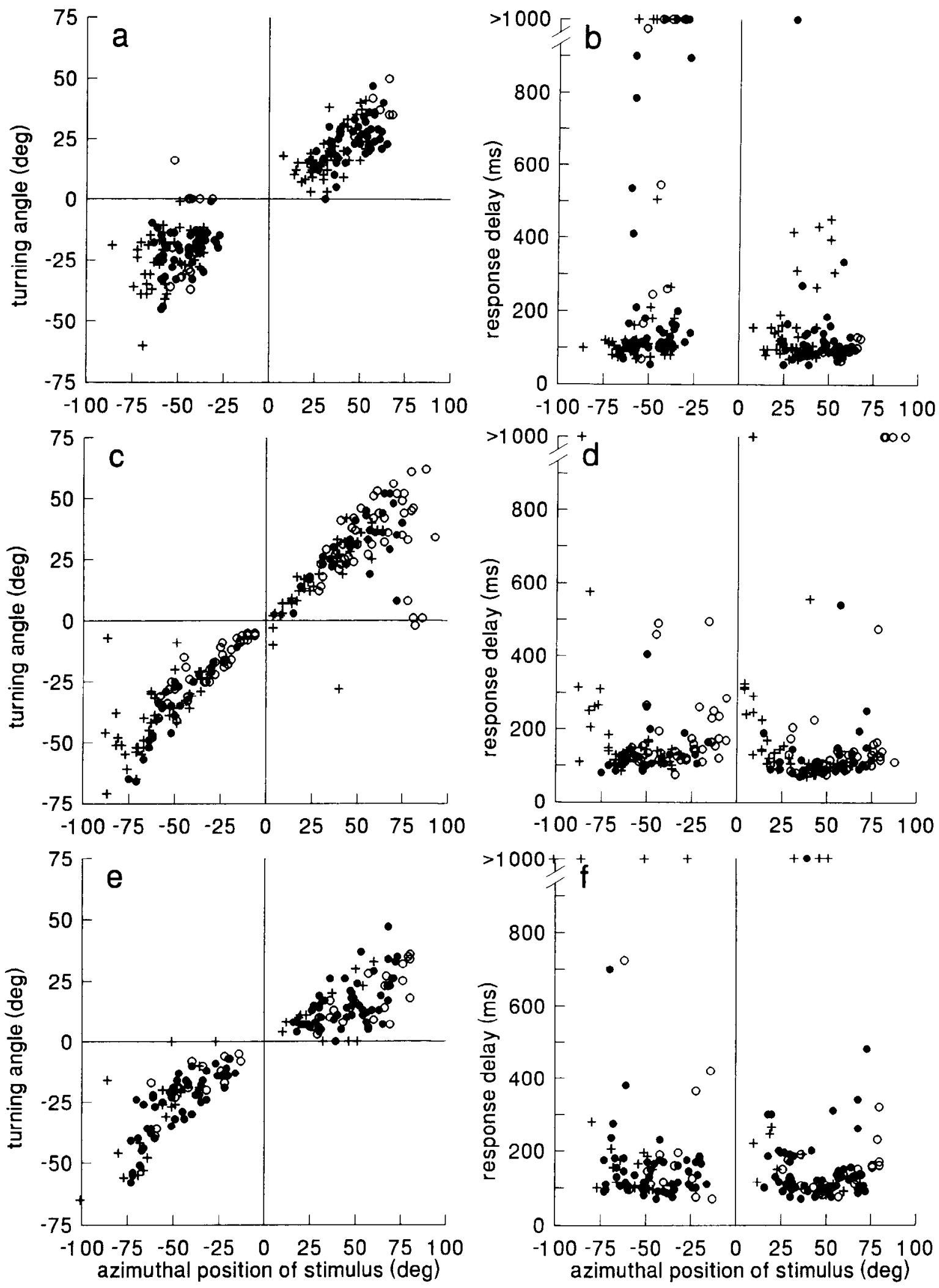

Figure 2. Sound-localization behavior before a lesion. Each scatter diagram contains about 200 trials for owl C $(a, b)$, owl M $(c, d)$, and owl $\mathrm{P}$ $(e, f)$. The azimuthal position of the stimulus and the turning angle were measured in owl-centered coordinates. Note the linear relation between the head-turning angle and the azimuthal position of the stimulus $(a, c, e)$ and the independence of response latency on the azimuthal position of the stimulus $(b, d, f)$. To test for a possible influence of the head orientation at stimulus onset, the data were divided into three subsets: open circles are from trials in which the head was initially oriented more than $5^{\circ}$ in azimuth to the left of the center of the external coordinate system. Pluses are from trials during which the initial head orientation was more than $+5^{\circ}$, and solid circles are from trials with the initial head position between $\pm 5^{\circ}$. Because stimuli were presented from 12 predetermined azimuths in the external coordinate system, the splitting introduced above led to slight shifts of the azimuthal positions of the stimulus. Initial head position did not influence the turning behavior. Since recording time was 2.5 sec, while all response latencies longer than $1 \mathrm{sec}$ were lumped in the $b, d$, and $f$, the number of failures to turn cannot be extracted from the scatter diagrams. 


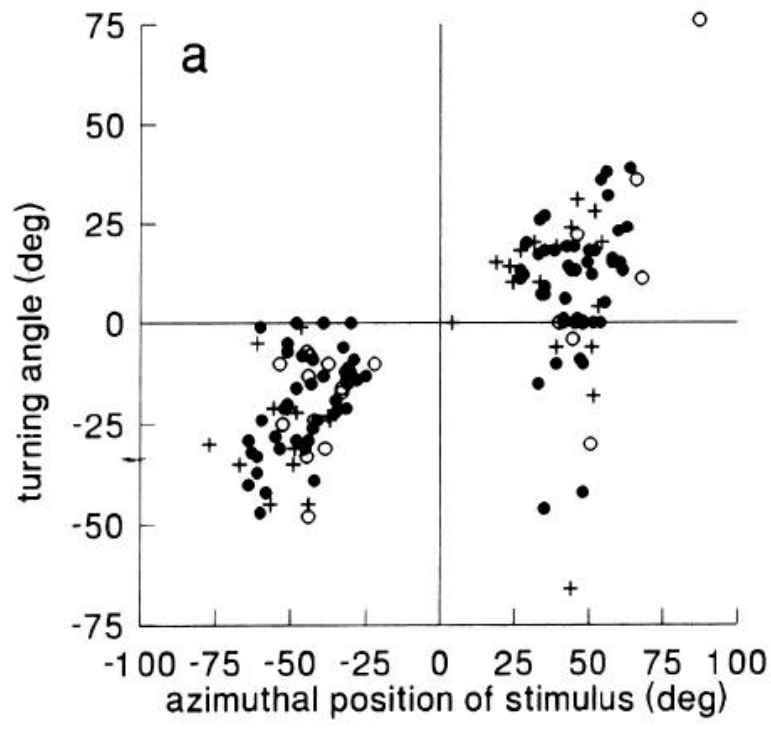

C

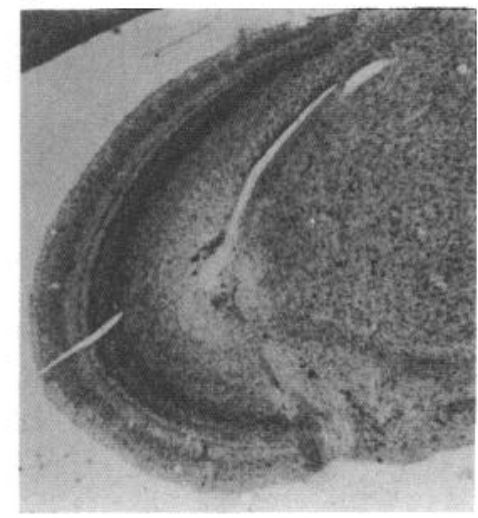

d

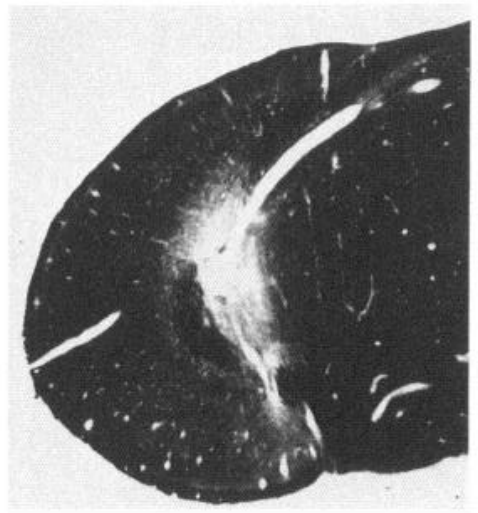

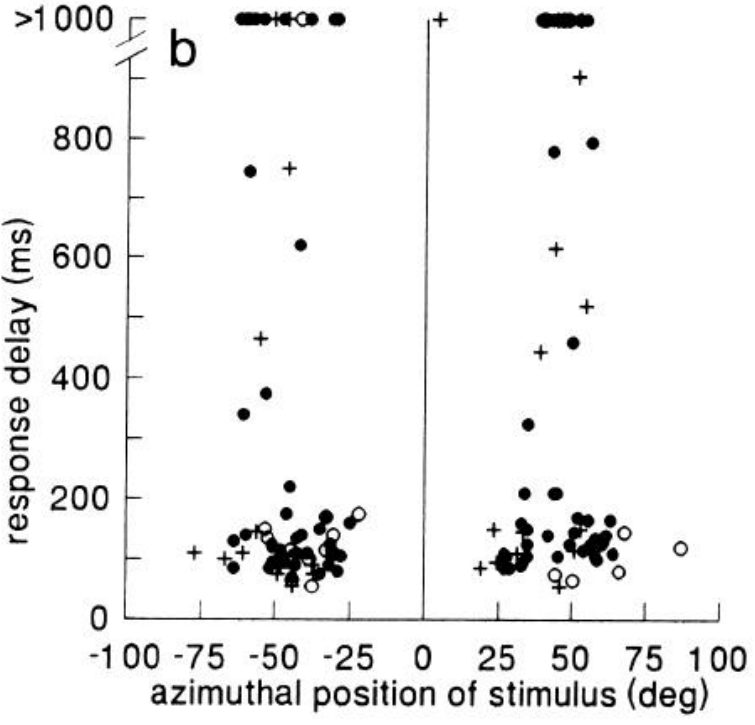

e

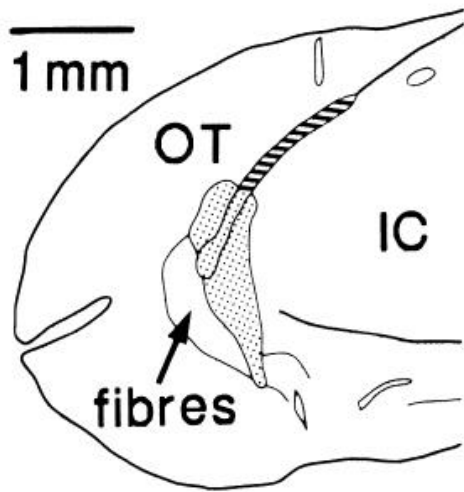

Figure 3. Sound-localization behavior of owl C after the first lesion. Test trials (142) were accumulated in the first $6 \mathrm{~d}$ after making the lesion. The lesion was placed at a locus in the map corresponding to about $+40^{\circ}$ (Table 2), and a specific deficit to stimuli from azimuths ranging from $35^{\circ}$ to $55^{\circ}$ can be seen $(a, b)$ if the responses are compared with the responses before the lesion (Fig. $\left.2 a, b\right)$. No lesion deficits occurred to stimuli from outside this restricted region (for statistics, see Table 1, owl C, after 1st lesion). Symbols are as in Figure 2. $c-e$, The lesion at its greatest extent. $c$, Nissl stain; $d$, LFB stain; and $e$, reconstruction. The lesion was largely restricted to the OT. IC, colliculus inferior. The fiber bundle marked by the arrow is the stratum album centrale of the OT. Scale bar in $e$ is also valid for $c$ and $d$.

\section{Localization behavior after lesioning}

On the day after a lesion was made, the owls did not show signs of nonspecific impairments when observed in their home cage. This impression was confirmed quantitatively in behavioral experiments following sham lesions placed outside ICx or OT in owls $\mathrm{C}$ and $\mathrm{P}$. In contrast, after a lesion in the space map (ICx or OT), specific behavioral deficits could be detected. These deficits occurred only at specific locations of the test stimulus. These locations corresponded to those that had been represented in the map by the lesioned areas (Figs. 3, 4; Tables 1, 2). In the example shown in Figure 3, a lesion was placed at a locus in the map that represented about $40^{\circ}$ of azimuth (Table 2 , case C1). A comparison of the behavior before the lesion (Fig. 2a) with the scatter diagrams compiled after the lesion (Fig. 3a,b) showed that the lesion caused a significant increase in the number of failures to turn when the stimulus position was around $+45^{\circ}$ of azimuth. Before the lesion, only 1 failure in 104 trails was observed when the stimulus was positioned to the right of the animal, whereas after the lesion the owl failed to turn in 9 out of 73 trials. With one exception, these failures occurred at stimulus positions between $40^{\circ}$ and $54^{\circ}$. For stimuli from the left side, the number of failures before and after lesioning were the same (five each). In addition, when the stimulus was positioned between $35^{\circ}$ and $55^{\circ}$ of azimuth, in owl-centered coordinates, the owl turned away from the sound source in 11 of 44 trials, while turns away from the sound source were absent on the unlesioned side. Altogether, the bird's behavior suggested that, when sound was broadcast from between $+35^{\circ}$ to $+55^{\circ}$ of azimuth, the owl turned at random after hearing a sound. Consistent with this impression, the mean value of the turning amplitude was around $0^{\circ}$ for stimuli from about $45^{\circ}$ of azimuth. With the statistical test the deficit could be clearly demonstrated over a range of about $20^{\circ}$, from $35^{\circ}$ to $55^{\circ}$ of azimuth (Table 1 , owl C, after 1st lesion). A similar conclusion could be drawn from the first lesion made in owl $M$ that was placed in the OT at a locus in the map representing about $+30^{\circ}$ azimuth (Fig. $4 c$; Table 1, owl M, after 1st lesion). Reliable testing was not possible in owl $\mathrm{P}$ in the week following the first lesion. After that time, the sound-localization behavior could not be discrimi- 

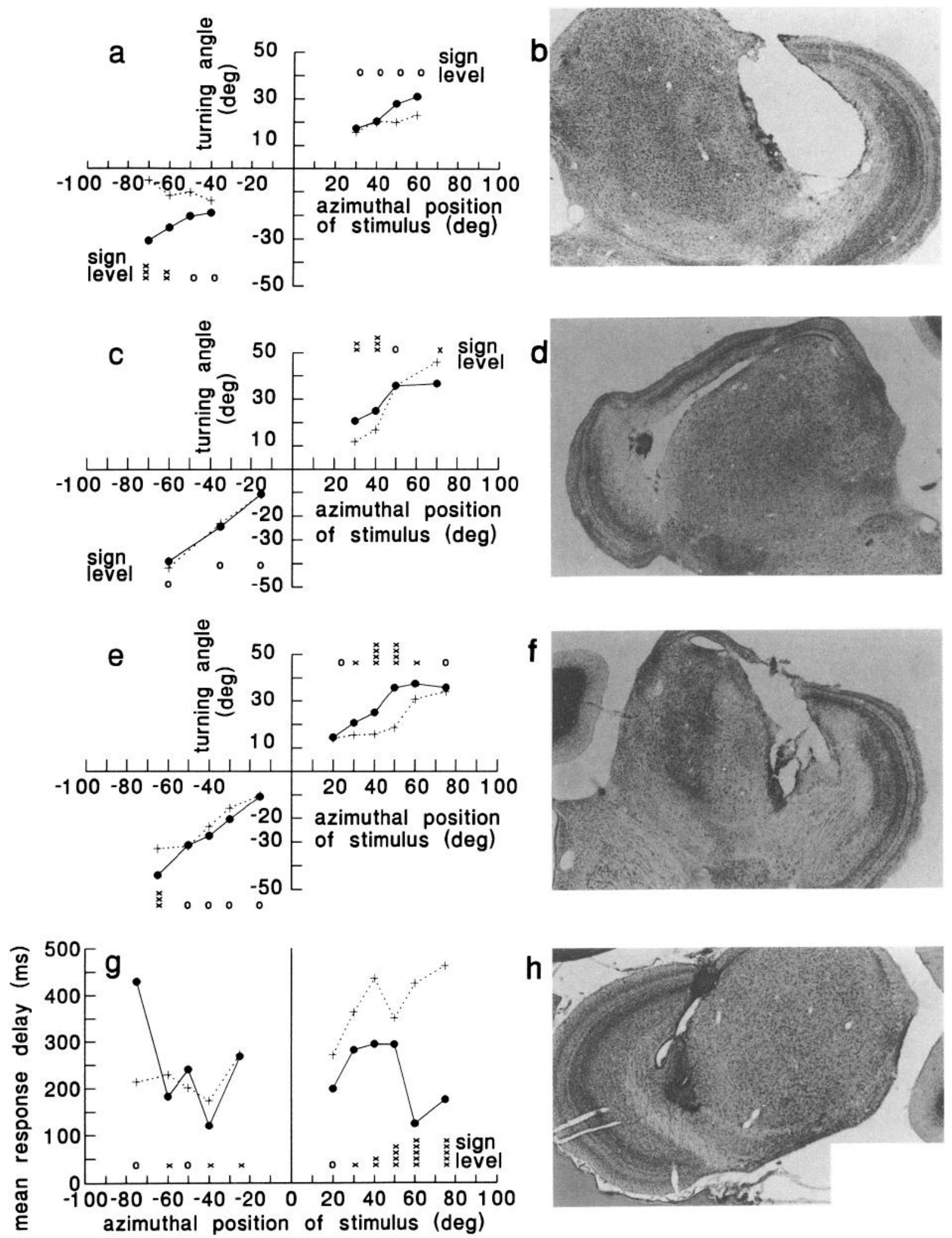

Figure 4. Effect of lesions. Data from four further lesions are shown $(a, \mathrm{C} 3 ; c \mathrm{M} 1 ; e, \mathrm{M} 2 ; g, \mathrm{P} 2)$. The data base included some 150 trials in each case. The mean values of the turning amplitude $(a, c, e)$ or the response delay $(g)$ before a lesion are plotted by the circles and solid lines. The mean values of the respective parameters after a lesion are shown by the crosses and broken lines. The significance level (obtained from a $U$ test) is shown above or below each measurement point: $O$ means no difference, $\times$ means significance at $p<0.05, \times \times$ means significance at $p<0.01$, and so on. The bins for the analysis were chosen such that at each measurement point at least 10 trials were included for each condition. Note that the deficits were specific and restricted to about $10-20^{\circ}$ in azimuth. In $b, d, f$, and $h$, photographs of the lesions at their greatest extent are printed. Note that in $f$, two lesions, $\mathbf{M} 2$ and $\mathbf{M} 3$, can be seen. Judged from the physiological responses at the lesion site and anteroposterior extent of the lesions, M3, of which the center is shown, corresponds to the more medioventrally lying branch of the hole, while M2, of which the anterior part 

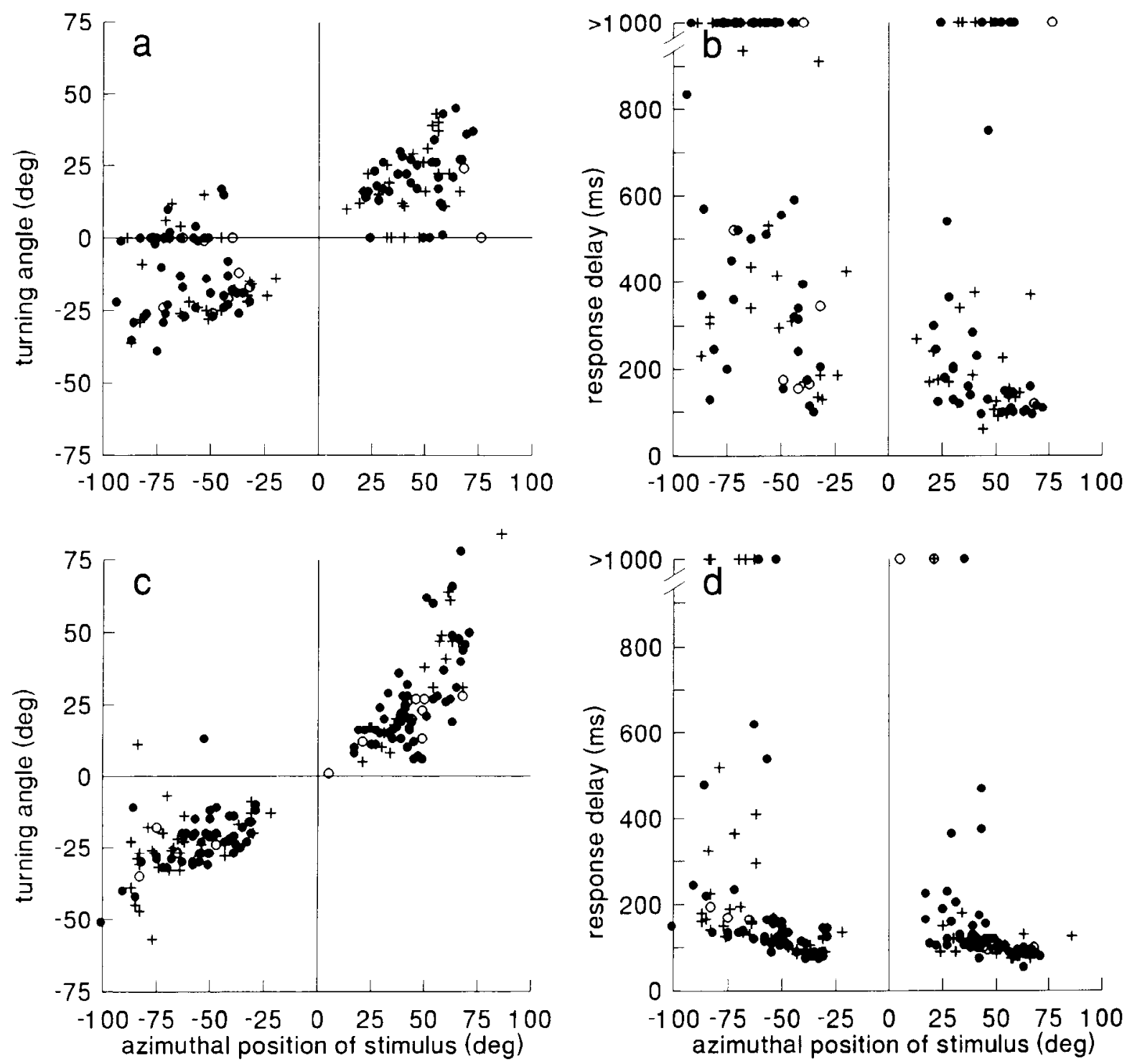

Figure 5. The deficit induced by the third lesion in owl $\mathrm{C}$ and the subsequent behavioral improvement. The same parameters as in Figures 2 and 3 are plotted. The data base was 151 trials for $a$ and $b$ and 171 trials for $c$ and $d$. The lesion was placed in the map at a locus representing about $-60^{\circ}$ of azimuth (Table 2, Fig. 11), and the deficit occurred between $-75^{\circ}$ and $-55^{\circ}$ of azimuth $(a, b ;$ see also Fig. $4 a)$. After $5 \mathrm{~d}$, the deficit had disappeared $(c, d)$, although the very short response latencies (Fig. $2 b)$ had not returned for azimuths farther left than about $-55^{\circ}(d)$. Note that there is no sign in the scatter diagrams of the deficit induced by the first lesion, that affected turns to the right (Fig. 3). Symbols are as in Figure 2.

nated from that before the lesion. Since the first lesion did not cause a measurable deficit in owl $P$, two data sets were recorded before the second lesion was made. From the comparison of these data sets (Table 1 , owl P, control), the naturally occurring variability was determined. The results were similar to those obtained in owl C (Table 1, owl C, control). As was the case before the lesions, there was no influence of initial head position on turning behavior after the lesions (Figs. 3, 5).

Since the lesion deficits were restricted to within one auditory hemifield, a further lesion could be made in the space map on the other side of the brain. These lesions resulted in deficits similar to the initial lesions (Table 1). For example, after the third lesion in owl $\mathrm{C}$ (the second being a sham lesion) that erased the representation of auditory space around $-60^{\circ}$ of azimuth, deficits were detected if the stimulus was positioned at azimuths ranging from $-75^{\circ}$ to $-55^{\circ}$ (Figs. $4 a, 5 a, b$; Table 1 , owl C, after 3 rd lesion). Note especially that, in the affected region, no response latency was below $300 \mathrm{msec}$ after the lesion (Fig. $5 b$ ).

There were both similarities and differences among the lesion deficits in the three owls. Unlike owl C, owls $M$ and $\mathrm{P}$ showed a less pronounced increase in the number of failures to turn. Owls $\mathrm{C}$ and $\mathrm{M}$ had clear deficits in both turning amplitude and response delay (Fig. $4 e, g$, Table 1), but in owl P only the response latencies were increased (Fig. 4g, Table 1, owl P, after 2nd

is shown, corresponds to the dorsolateral branch of the lesion. The position of the lesions are given in Table 2. Note that a complete reconstruction is provided for the cases C3 (Fig. 9) and P2 (Fig. 10). The photograph shown for case C3 (b) corresponds to section 133 in the coordinate system explained in the Figure 9 caption. The photograph shown for case P2 $(h)$ corresponds to section 79 . Photographs were taken from Nissl stains. The scale bar in $h$ is valid for all photographs. 
Table 1. Effect of lesions

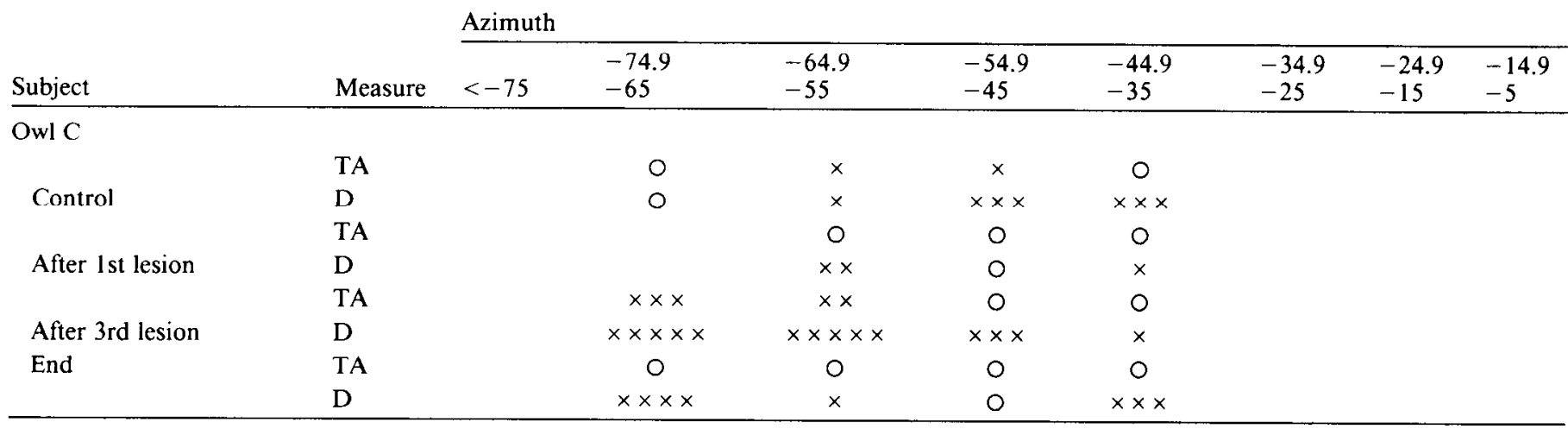

Owl M

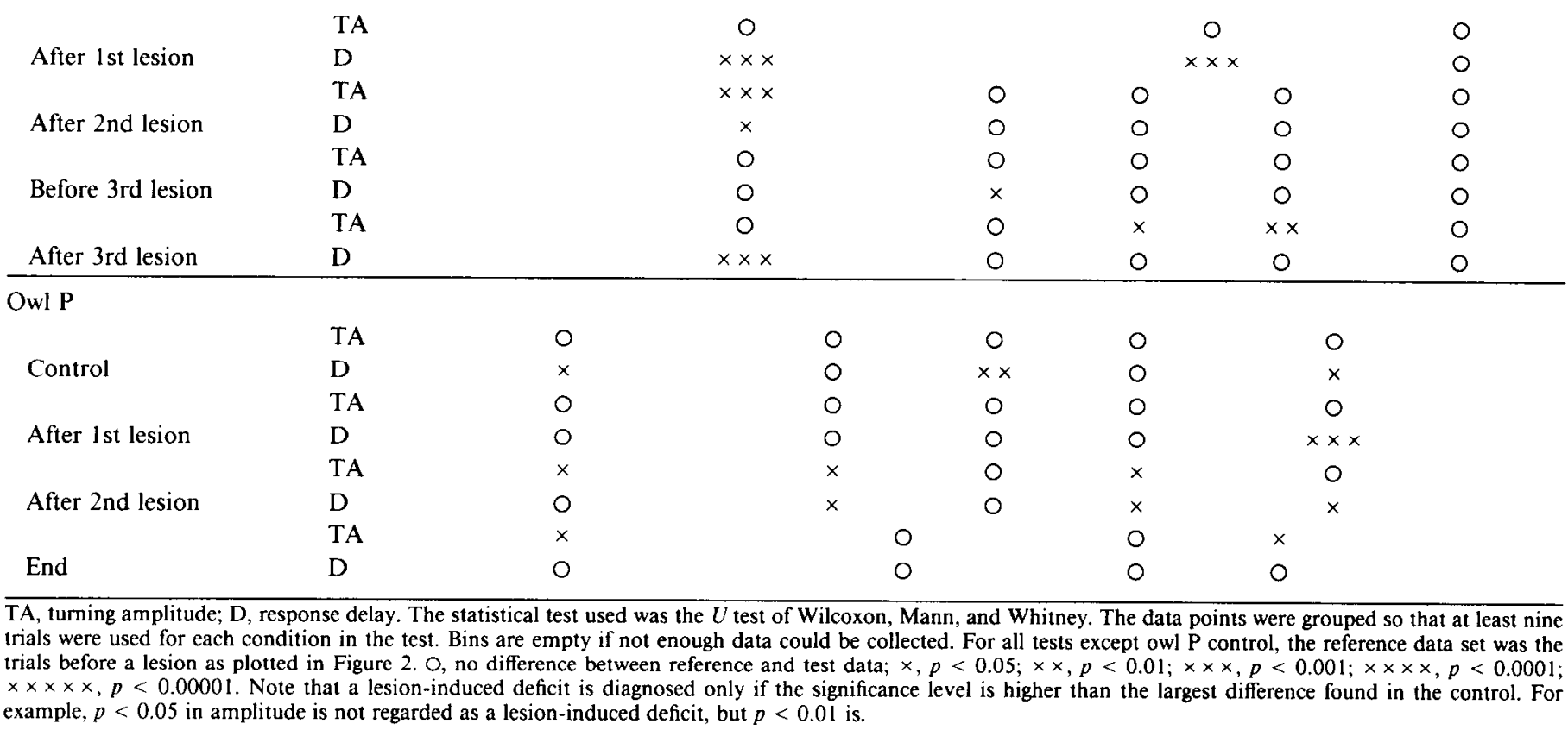

lesion). In owl M, a third lesion was placed in the $\mathrm{ICx}$ (Fig. 4d). No deficit was detected after that lesion (Table 1, owl M, after 3rd lesion).

\section{Period of improvement}

The data presented so far were obtained in the first week following the lesion. After that time, a considerable improvement of the reaction to sounds from the affected regions of auditory space had occurred. This can be seen in the scatter diagrams of Figure 5, $c$ and $d$, which show the behavior of owl $C$ in the period from 6 to $13 \mathrm{~d}$ after the third lesion. Most notably, the response latencies to sounds from about $-60^{\circ}$ became shorter again (Fig. 5d). Note also that after the third lesion no deficit could be detected in the right hemifield, corresponding to positive azimuths. Thus, the deficit induced by the first lesion had completely disappeared (Fig. 5; Table 1, owl C, after 3rd lesion and end).

In total, nine lesions were made, three in each animal. The two sham lesions $(C 2, P 3)$ and two further lesions (P1, M3) did not produce a deficit. In three of the remaining five cases, turning amplitudes improved to prelesion levels (Fig. 6), and a partial improvement was seen in a fourth case (Fig. 7a).

After the second lesion in owl P no signs of a improvement were visible within 7 weeks (Fig. $7 b$ ). Since an improvement had occurred within this period in all other cases, it was concluded that the deficit was permanent, and the bird was killed to study the locus and extent of the lesion. In the total testing period after the lesion was made, the very short latencies were missing in the reactions of this bird. A similar observation was made in owl $C$ after the third lesion, when also no very short latencies could be measured in the affected region (around $-60^{\circ}$ ) after the period of improvement of turning amplitudes (compare Fig. $5 d$ with Fig. $2 b$ ). If, from the trials obtained in the final period, only those $50 \%$ of the turns having the shortest latencies were considered, the mean latency to stimulation from the affected regions of auditory space was increased by more than 30 msec in both cases (from $84 \mathrm{msec}$ to $128 \mathrm{msec}$ in owl C and from $104 \mathrm{msec}$ to $139 \mathrm{msec}$ in owl P).

The time course of the recovery was quite variable ranging from $5 \mathrm{~d}$ (case C3) over $17 \mathrm{~d}$ (case M2) to more than $20 \mathrm{~d}$ (case Cl) (Fig. 6). Improvements after the second or third lesions followed the same time course as did the improvements after the first lesions. In two cascs, the birds improved gradually until a deficit was no longer measurable (Fig. $6 a, c$ ). The initial time course of improvement in the case with partial improvement (Fig. 7a) was similar to the time courses of the cases showing a 
Table 1. Continued

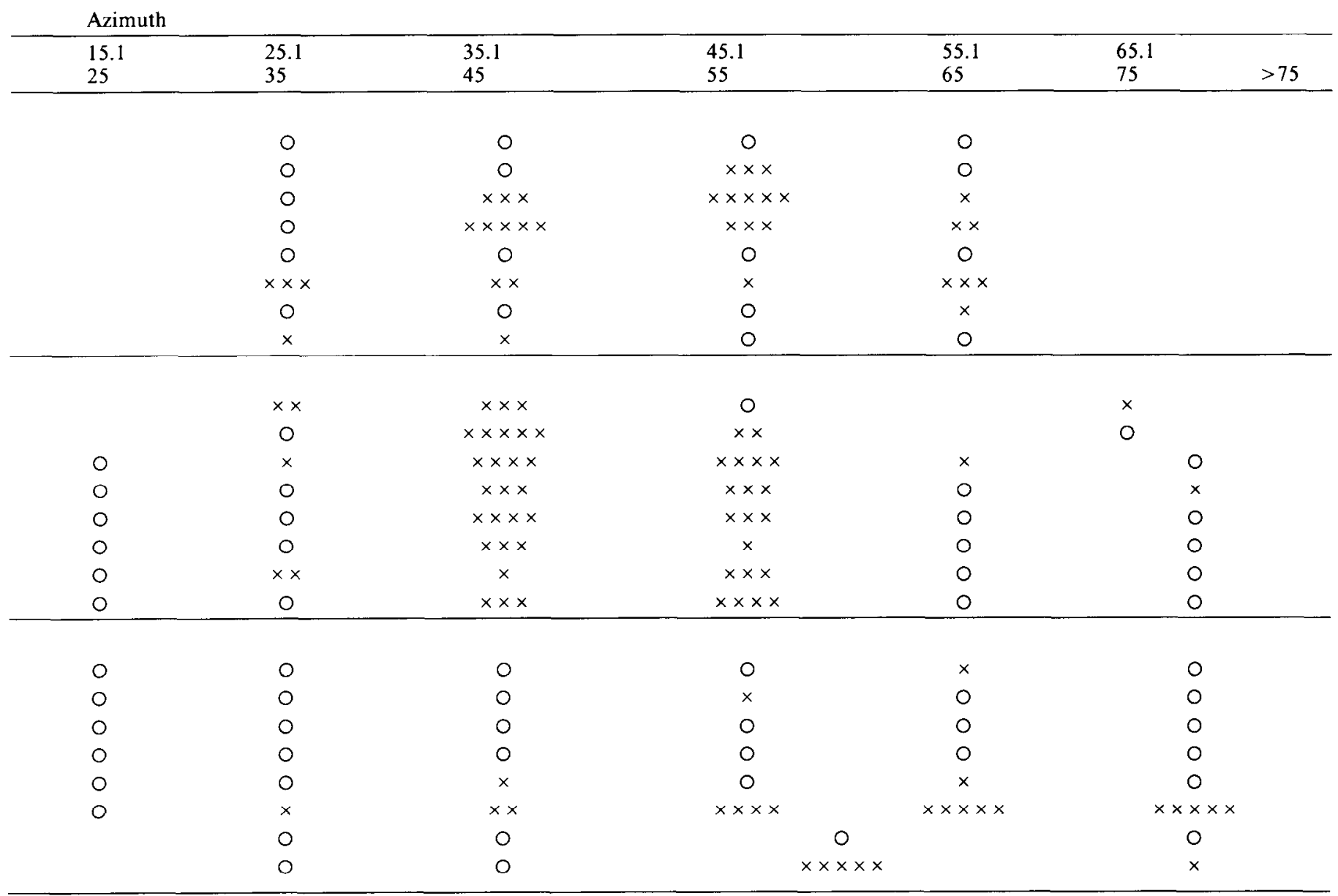

complete improvement (Fig. 6). In one case, an abrupt change was seen (Fig. $6 b$ ) after $5 \mathrm{~d}$ of impairment.

The data for owl $\mathrm{C}$ were obtained at $30 \mathrm{~dB}$ above hearing threshold. Therefore, after recovery had occurred at that sound level, the owl was also tested at lower levels to see if, for low sound levels, a lesion deficit had remained. The hearing-threshold curve of owl $C$ after two lesions in the space map was compared with the hearing-threshold curve of owl $\mathrm{P}$ before any lesion (Fig. 8). The probability of turning toward the sound source was used as a criterion. For sound levels higher than 0

Table 2. Correlation between physiology, anatomy, and behavior

\begin{tabular}{|c|c|c|c|c|c|c|c|c|}
\hline \multirow[b]{2}{*}{ Case $^{a}$} & \multirow{2}{*}{$\begin{array}{l}\text { Behavioral } \\
\text { deficit }\end{array}$} & \multicolumn{4}{|c|}{ Physiological correlates ${ }^{b}$} & \multicolumn{3}{|c|}{ Lesion anatomy } \\
\hline & & ITD $(\mu \mathrm{sec})$ & ILD & Freq & SS & Locus & Extent & Deg \\
\hline $\mathrm{Cl}$ & $35-55$ & $60 / 90$ & $?$ & 8 & + & OT(ICx) & $16-31$ & $30-50$ \\
\hline $\mathrm{C} 3$ & -75 to -55 & -120 & + & 7 & + & $\mathrm{ICx}(\mathrm{OT})$ & $7-35$ & -65 to -25 \\
\hline M1 & $25-55$ & 60 & + & 8 & + & OT & $11-36$ & $25-55$ \\
\hline M2 & -75 to -50 & $-90 /-120$ & t & 5 & - & OT(ICx) & $0-15$ & $>-50$ \\
\hline M3 & No deficit & -90 & + & 9 & + & $\mathrm{ICx}$ & $9-36$ & -60 to -25 \\
\hline $\mathrm{P} 1$ & Unclear ${ }^{d}$ & -120 & + & 2 & $?$ & $\mathrm{ICx}$ & $12-22$ & -55 to -40 \\
\hline $\mathrm{P} 2$ & $>+45$ & 120 & $?$ & 8 & + & $\mathrm{ICx}$ & $15-30$ & $30-50$ \\
\hline
\end{tabular}

${ }^{a}$ As defined in Materials and Methods.

"ILD, response tuned to interaural level difference $(+)$ or not $(-)$; Freq $(\mathrm{kHz})$, highest frequency measured near lesion site; SS, side-peak suppression upon noise stimulation present $(+)$ or not $(-)$.

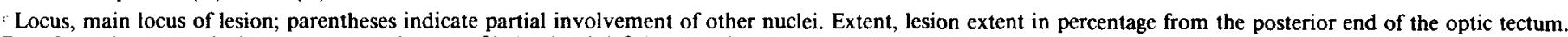
Deg, from the anatomical extent, expected range of behavioral deficit according to the tectal map by Knudsen (1982).

"Unclear whether a deficit was initially there (see also Results). 

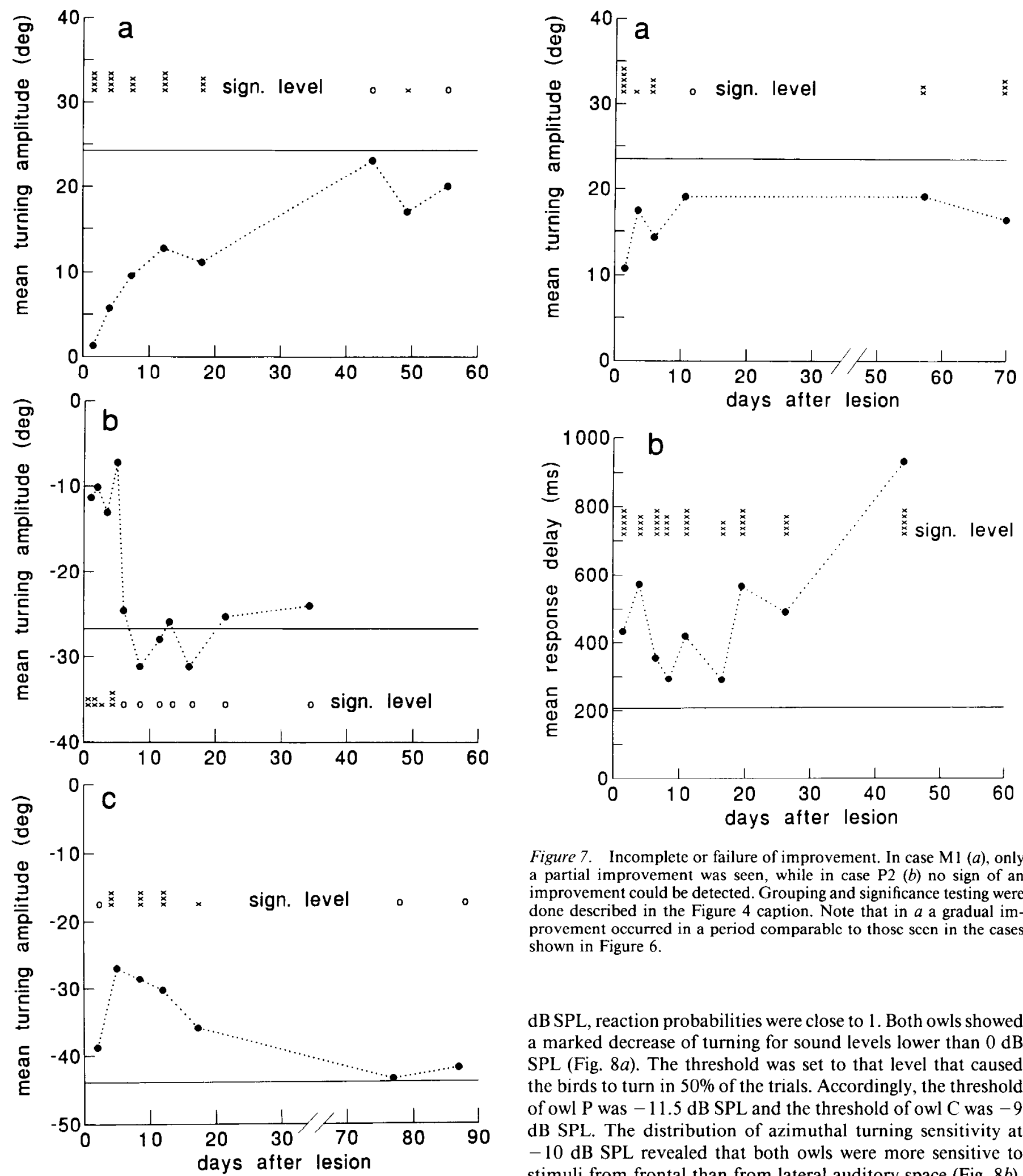

Figure 7. Incomplete or failure of improvement. In case M1 (a), only a partial improvement was seen, while in case P2 $(b)$ no sign of an improvement could be detected. Grouping and significance testing were done described in the Figure 4 caption. Note that in $a$ a gradual improvement occurred in a period comparable to those secn in the cases shown in Figure 6.

dB SPL, reaction probabilities were close to 1 . Both owls showed a marked decrease of turning for sound levels lower than $0 \mathrm{~dB}$ SPL (Fig. 8a). The threshold was set to that level that caused the birds to turn in $50 \%$ of the trials. Accordingly, the threshold of owl P was $-11.5 \mathrm{~dB}$ SPL and the threshold of owl C was -9 $\mathrm{dB}$ SPL. The distribution of azimuthal turning sensitivity at $-10 \mathrm{~dB}$ SPL revealed that both owls were more sensitive to stimuli from frontal than from lateral auditory space (Fig. 8h), but no specific impairment to stimulation from those regions

Figure 6. Time course of behavioral improvement. In three cases ( $a$, $C 1 ; h, C 3 ; c, \mathrm{M} 2$ ), the turning amplitude reached the prelesion level after some time. This is demonstrated here by plotting the mean turning amplitude after a lesion (solid circles and broken lines) as a function of time. The ranges of azimuths selected for this plot were those in which an effect of the lesion was observed (Table 1). The solid lines represent the mean turning amplitudes before a lesion. The grouping and significance testing are described in the Figure 4 caption. of auditory space that had been deleted from the map was observed in owl C.

Anatomy

The space map extends from anteromedial to posterolateral and has an overrepresentation of frontal auditory space in both the ICx and the OT (Knudsen and Konishi, 1978b; Knudsen, 1982). 
The most (contra)lateral loci are represented at the most posterior loci in the brain.

Lesions extended over approximately 1-2 mm. As was expected from the fact that current was passed at several positions along a dorsoventral tract, the lesions were often elongated in the dorsoventral axis. Three lesions were confined to the space map in the ICx (Table 2, Fig. $4 d, h$ ), one lesion was located in the deeper layers of the OT (Table 2, Fig. 4d), and the remaining three lesions extended over both nuclei (Table 2; Figs. 3c-e, $4 b, f)$. Destruction of the ICc was minor in all cases. Neither the type of deficit nor the time course of improvement depended on the site of the lesion (Figs. 3-7).

An example of how reconstructions were made is shown in Figure $3 c-e$. Lesioned regions were assessed by comparing Nissl and LFB stains, and by using a reference brain. In this case, the lesioned region was more easily visible in the LFB stain (Fig. $3 d$ ), and therefore the fiber stain was used to assess the extent of the lesion (Fig. 3e). In other cases, Nissl stains provided equally good estimates of the size of the lesions (Fig. $4 b, d, f, h$ ). In general, the information contained in both stains was combined for reconstruction.

The third lesion in owl $C$ was located in the posterior part of the space map and extended over about $30 \%$ of the map (Fig. 9. Table 2). This was the largest lesion. At its largest extent (Fig. $4 b$, Fig. 9, sections 121-133), it erased most of the ICx. The lesion encroached into the OT, hitting the deeper layers in the middle of the dorsoventral extent (corresponding zero elevation), and posteriorly the superficial layers at the dorsal surface (corresponding to sound from high elevations). In addition, a very small part of the low-frequency region of the ICc may have been lesioned (Fig. 9, section 121).

The second lesion in owl P (Figs. 4h, 10) erased most of the ICx in the posterior part of the nucleus (Fig. 4h, Fig. 10, sections 77-86), while it almost completely spared the surrounding nuclei ICc and the OT. The lesion was located on the opposite side of the brain at a position in the map similar to that of the lesion shown in Figure 9. The behavioral deficit extended over a similar, but mirror-symmetric, region of auditory space (Table 1, Fig. $4 a, g$ ).

The reconstructions of the lesions showed a good correspondence between the azimuthal range of the behavioral deficit and the azimuthal range represented by the lesioned part of the nucleus. The expected range of azimuths represented by the affected tissue was calculated from the auditory map of the OT (Knudsen, 1982), and this expected range was compared to that observed in the behavioral tests (Table 2). In all cases, the expected ranges largely overlapped with the observed ranges, and the center of the observed deficit was always included in the expected ranges. The most posteriorly located lesions (C3, P2, M2) led also to the most lateral deficits (Table 2). Minor discrepancies were that, in some cases, the center of the observed deficit was not in the center of the expected range. These minor discrepancies may be explained by the fact that no detailed map was available for ICx, and that the tectal map becomes increasingly coarser for loci lateral to $40-50^{\circ}$.

\section{Electrophysiology}

In this study, electrophysiological recordings served ońly to guide the electrode to the correct lesion site. It is instructive, however, to consider also the correlation between physiology and behavior. These comparisons are based on previously reported measurements, in which it was found that $1^{\circ}$ in azimuth corresponds
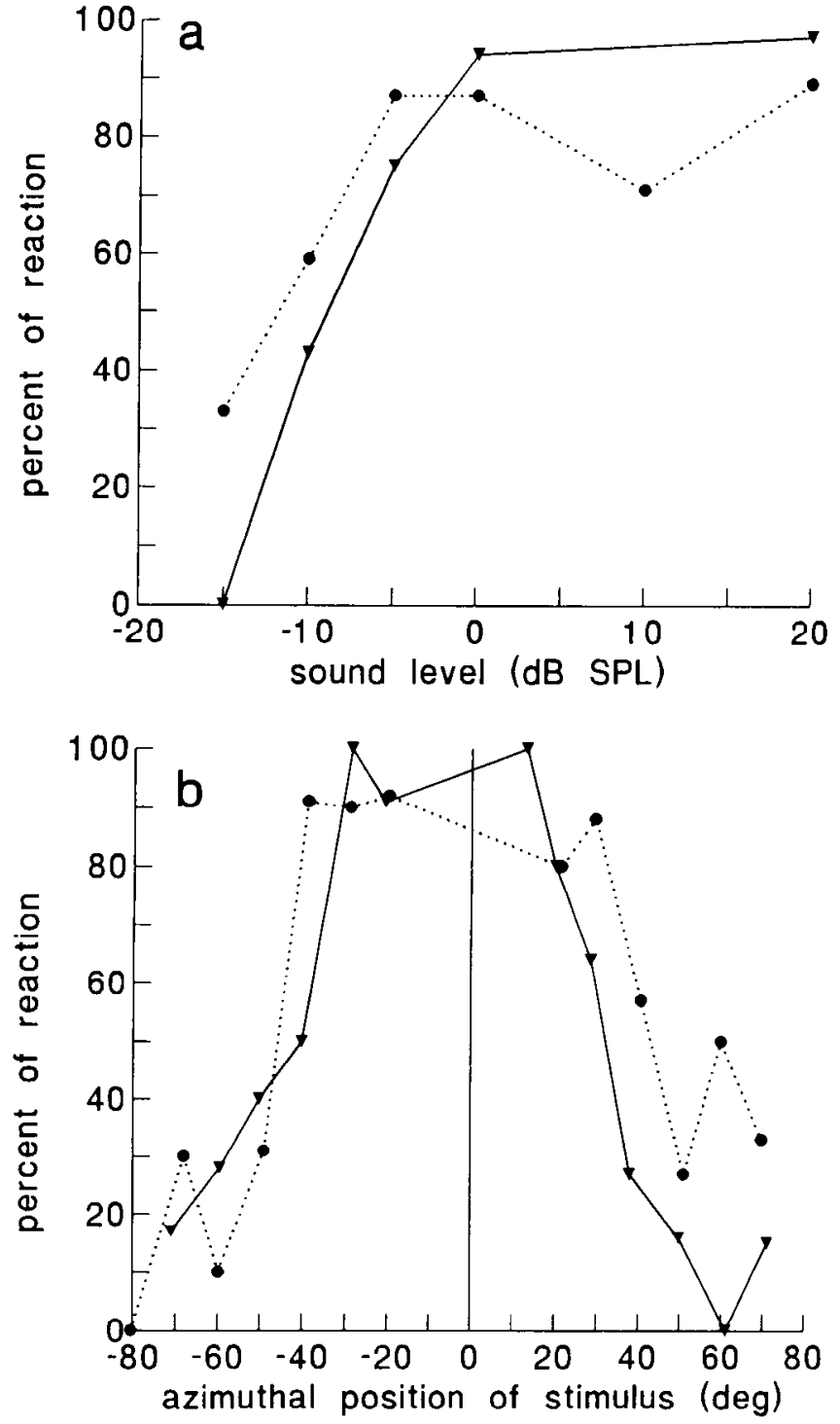

Figure 8. Hearing threshold. $a$, Overall threshold. The hearing threshold of owl C (triangles and solid lines) was determined after two lesions had been made in the space map, while that of owl P (circles and broken lines) was measured before any lesion was made. The mean values of the percentage of reactions are shown. The hearing threshold was defined as those sound levels at which the owl reacted in $50 \%$ of the test stimuli. Note that in the two owls the threshold is similar. $b$, Azimuthal dependence of the reactions near the hearing threshold. Reactions were recorded at $-10 \mathrm{~dB}$ SPL stimulus level. Note the decreased percentage of reactions for peripheral sounds.

to about 2-2.5 $\mu \mathrm{sec}$ of ITD (Moiseff and Konishi, 1981; Moiseff, 1989; Olsen et al., 1989). There was a good correspondence between physiology and behavior in all those cases $(\mathrm{Cl}, \mathrm{C} 3, \mathrm{P} 2$, M1) in which high-frequency regions (up to $9 \mathrm{kHz}$ ) were found (Table 2). For example, in case C3, tuning to both ITD and ILD was found at the lesion site, and the ITD tuning to noise stimuli had only one peak, whereas the response to a tonal stimulus had several equivalent response peaks (Fig. 11). Therefore, it was concluded that the recording site was beyond the lateral shell of the ICc, in either ICx or OT (for more details on the neural responses in the time pathway, see Knudsen and Konishi, 1978b; Moiseff and Konishi, 1983; Wagner et al., 1987; Takahashi et al., 1989; Fujita and Konishi, 1991). The response 
Figure 9. Reconstruction of the third lesion in owl C. The lesion caused a total destruction of the tissue (dark shading) and skirts of partially affected tissue, including areas with missing somata or fibers (light shading). Numbers of the 30- $\mu$ m-thick sections are shown on the top right of each section. They increase from posterior to anterior. The orientation of the brain sections is indicated at the upper right: $l$, lateral; $a$, anterior; $d$, dorsal. The drawings were made with reference to Nissl and LFB stains. The unaffected brain shape, especially the position of the ventricle, was reconstructed by means of a reference brain and is indicated by the broken lines. The behavioral deficit induced by this lesion is shown in Figures $4 a$ and $5 a, b$, and a photograph of section 133 is shown in Figure $4 b . I C$, inferior colliculus; $I C C$, central nucleus of the inferior colliculus; ICS, superficial nucleus of the inferior colliculus; $I C X$, external nucleus of the inferior colliculus; $O T$, optic tectum; $F R L$, formatio reticularis lateralis mesencephali; $I M C$, nucleus isthmi, pars magnocellularis; $I P C$, nucleus isthmi, pars parvocellularis. Note that the lesion is located in posterior part of the tectal lobe covering both the ICx and the OT.

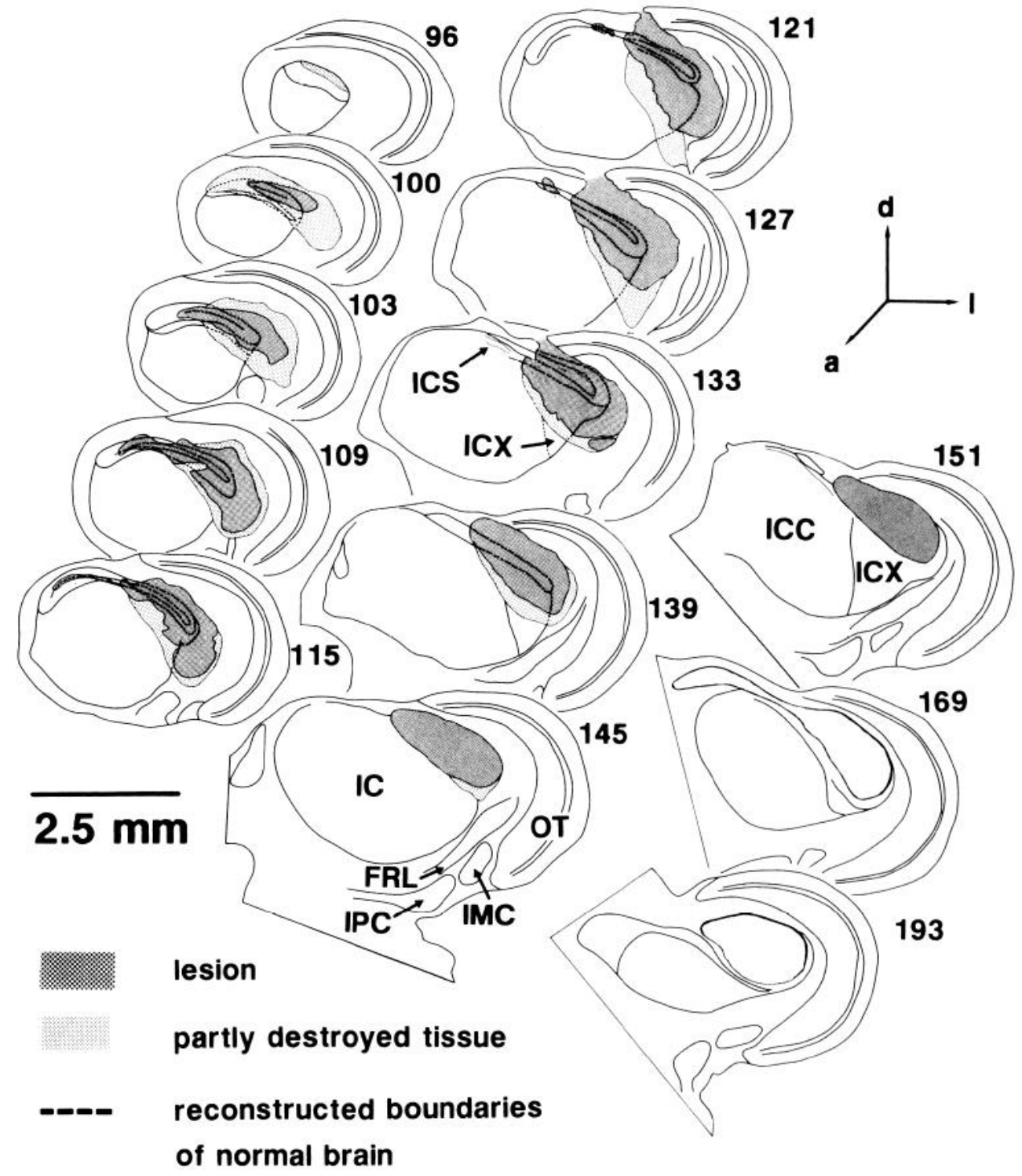

peak in the noise curve occurred around $-120 \mu \mathrm{sec}$, which led to the prediction that a behavioral deficit should be found around $-60^{\circ}$ of azimuth. This was exactly the case (Figs. $4 a, 5$ ).

In two cases (P1, M2), only low-frequency regions (up to 5000 $\mathrm{Hz}$ ) could be recorded (Table 2). In P1 the occurrence of a deficit remained unclear, and the deficit found in case M2 appeared further lateral than expected from the relation cited above. However, the anatomy showed that the lesion site in this case was located far posterior. This is consistent with the findings of Knudsen (1984), who showed that low frequencies were overrepresented in coding lateral space.

\section{Discussion}

After a lesion in the owl's ICc-ICx-OT pathway, I observed a local and transient behavioral deficit characterized by failures to turn toward stimuli; turns in the wrong direction, that is, away from the sound source; increased response latencies; and reduced turning amplitudes. Since peripheral structures were not affected, the owl could still hear the sound, but it seemed unable to localize the source. Thus, the deficit induced by the lesion is a "true" localization deficit.
Generally, it is easier to interpret behavioral data that are obtained by studying permanent lesion deficits, because data can be collected over a long time, and lesion extents can be correlated in an easy way with the behavioral deficits. Here I observed mainly transient effects. This was possible by keeping electrophysiological experiments short and making only relatively small lesions. The results demonstrated that these transient deficits are as interesting as permanent deficits, because they allow conclusions not only about pathways (as the permanent lesions do), but also about recovery and its underlying mechanisms.

\section{Nature of the deficit}

Since only transient localization deficits were observed, it might be argued that the deficits represented some undefined artifact and not "true" sensory deficits. Such a possibility can be ruled out, however, for the following reasons.

First, the lesions caused a destruction of the brain area under investigation. The region of auditory space that was erased from the space map by the lesions could be determined by comparing the size of the lesioned area with the physiological map of the 
65

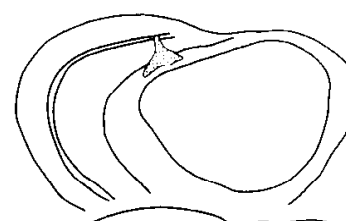

68

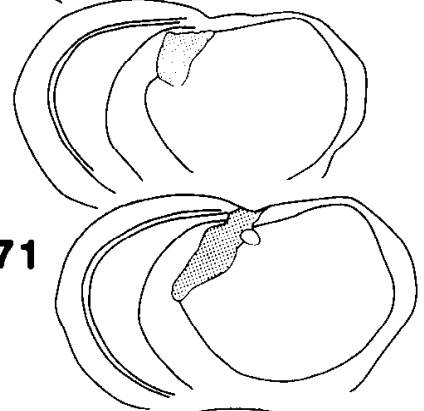

74

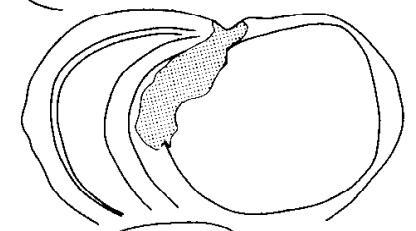

77

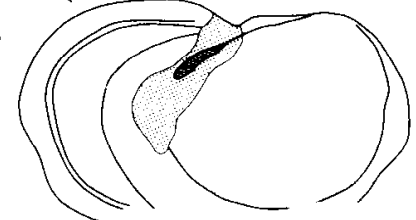

80

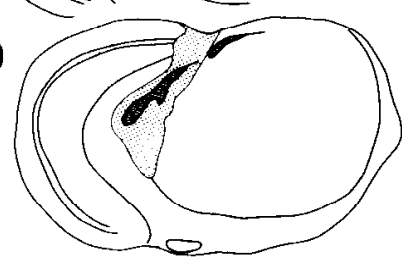

partly destroyed tissue

ventricle
83

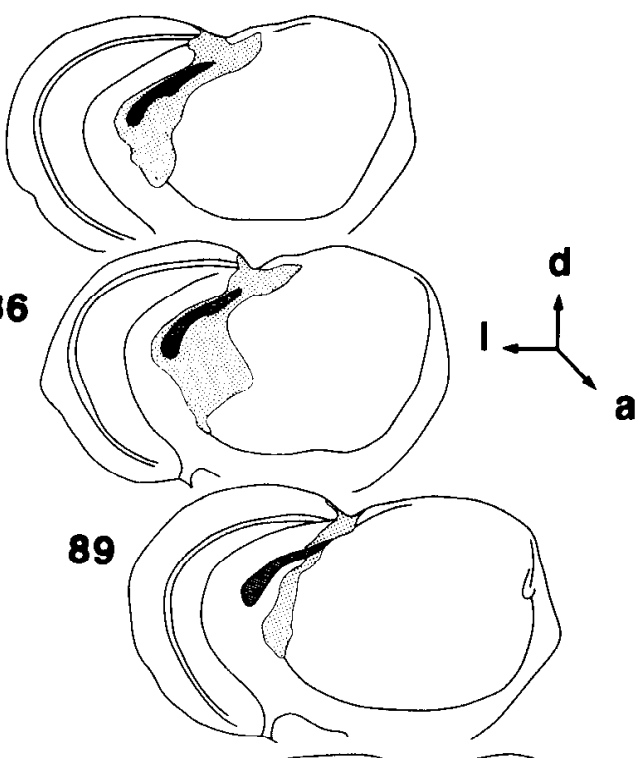

92

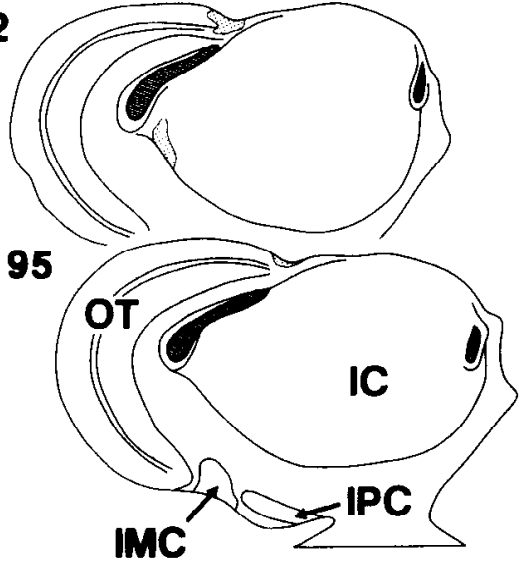

$2.5 \mathrm{~mm}$
Figure 10. Reconstruction of the second lesion in owl P. Methods and symbols are the same as for Figure 9 . The behavioral deficit induced by this lesion is shown in Figure $4 g$, and a photograph of section 79 is shown in Figure $4 h$. This lesion is almost exclusively restricted to ICX.
OT (Knudsen, 1982; see Table 2). Since the correspondence between the measured azimuthal extent of the behavioral deficit and the region expected from the above comparison was good (Table 2), it can be excluded that effects induced by ischemia, neural shock, or other indirect effects of the lesions such as edema in nearby structures were the primary cause of the behavioral deficits. Such effects might, however, have added to the lesion effects. While an indirect effect on the ICc-Ov-L pathway would have been possible from the lesions in the space map of ICx, such an effect is very unlikely for lesions in the OT, because the ventricle behaves as a shunt for the current. Since lesions in both the ICx and OT led to the same results, it is concluded that the behavioral deficits were not due to an indirect effect on the ICc-Ov-L pathway.

Second, one might suspect that the motor rather than the sensory aspects of the head-turning behavior were impaired by the lesion. Barn owls possess four saccade generators that control head movements, one for each main direction, up, down, left, and right (Masino and Knudsen, 1990). The properties of these saccade generators can be studied by tectal stimulation, but the generators themselves are located after the OT. If one of these saccade generators or its precursors were affected by a lesion, an impairment for either turns to the left or turns to the right would be expected. In this study, however, the affected turns were confined to stimulation from a region of about $20^{\circ}$ within one hemifield with little indication of a deficit beyond the affected areas in the same hemifield. Thus, motor impairment can be ruled out.

Third, the owls could have made up for their deficits by scanning with their heads. This was not observed in this study, and also not in previous studies (Payne, 1971; Fig. 3 in Knudsen et al., 1979; Figs. 1, 3, and 8 in Du Lac and Knudsen, 1990). Rather, the owls kept their heads fixed before the onset of the test stimulus, and test trials in which the owls rotated the head by more than $2^{\circ}$ during the first $50 \mathrm{msec}$ after the onset of the test stimulus were not used for the analysis.

Fourth, in earlier experiments on sound localization in cats, it was observed that these animals learned to respond tactically (for a discussion of this issue, see Jenkins and Masterton, 1982). That is, in a two-sided test, the animals learned to associate "unlocatable sounds" with the lesioned side. This tactic would not have worked when the stimulus came from many different 

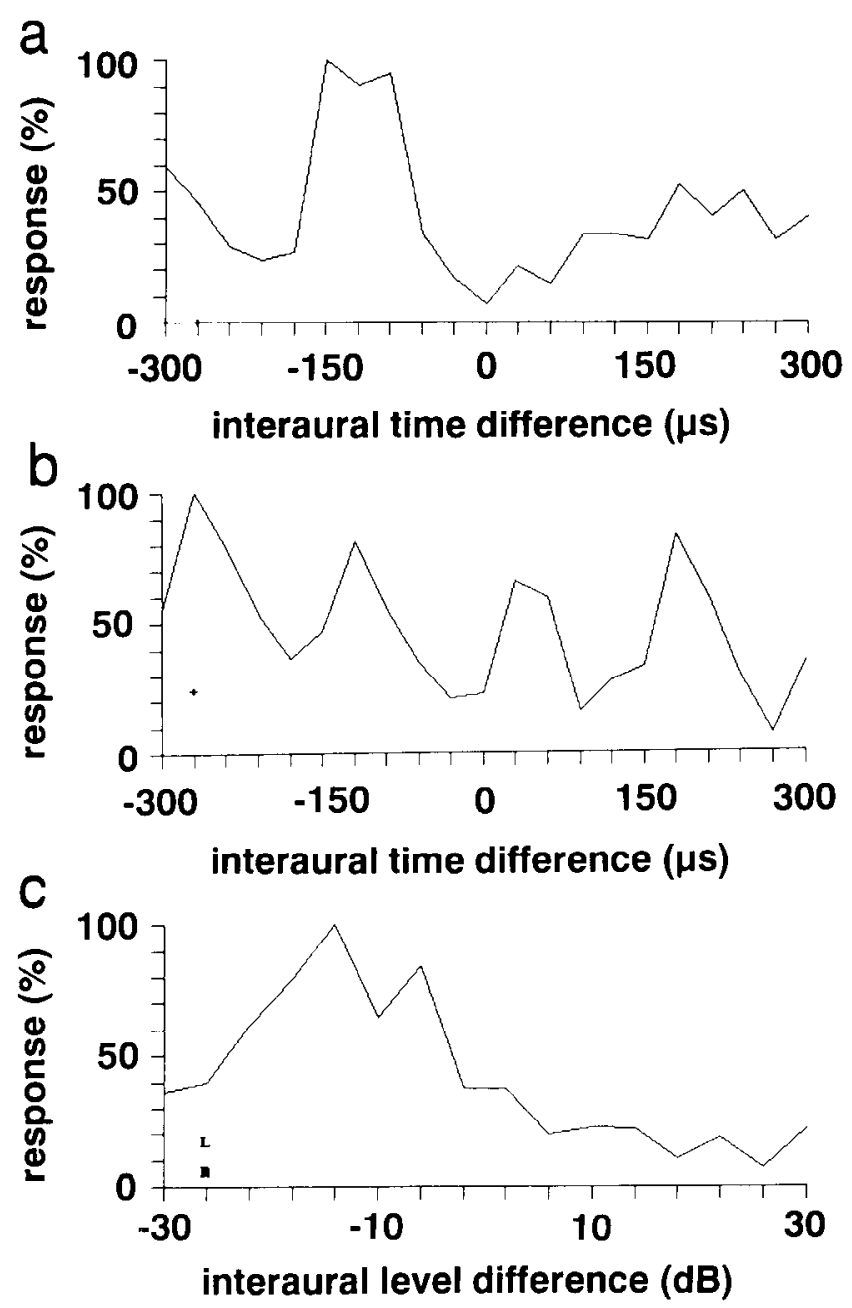

Figure 11. Electrophysiological responses at the site of the third lesion in owl C. At the site of the lesion a multiunit response showed the highest spike activity in response to noise stimulation around -120 $\mu \sec (a)$. Upon stimulation with a tone of $6667 \mathrm{~Hz}$, several peaks were observed $(b)$. logether, these results led to the conclusion that the recording was from a level higher than the ICc. The tuning to ILD (c) supports this conclusion. The plus marks the spontaneous activity, and $R$ and $L$ mark the monaural responses to stimulation of the right and left ear alone. Since $-120 \mu \mathrm{sec}$ corresponds to about $-60^{\circ}$ in azimuth, a lesion deficit around this angle was expected.

azimuths in each hemifield. Especially after the second lesion, such a tactic would fail: under the assumption that the improvement after the first lesion was due to tactical learning, sounds would have been unlocatable in two regions after the second lesion. This should have led to about $50 \%$ turns away from the sound source when the stimuli originated from the affected regions. However, the behavioral changes occurring after the second lesion were very similar to the behavioral changes occurring after the first lesion. A further tactic could have been, in cases with a centering stimulus, random turning after the centering stimulus, because this would still have yielded a reward in $50 \%$ of the trials. To test whether the bird behaved in this way, "catch trials" with a stimulus level below the owl's hearing threshold were used in one owl. During such trials, the owl responded with a turn to a centering stimulus from directly in front, but it did not turn a second time in expectation of the test stimulus. Thus, tactical responding can also be ruled out.

\section{Neural hasis of sound localization}

My data demonstrate that after lesions in the ICc-ICx-OT pathway, the owls' sound-localization behavior was impaired. Thus, this pathway is important for sound localization. Consistent with this conclusion, head turns can by elicited by electrical stimulation in the OT (Du Lac and Knudsen, 1990; Masino and Knudsen, 1990). However, because the auditory map in the tectum is in register with a visual map, a separation of visual and auditory information is not possible by electrical stimulation. Thus, stimulation experiments can provide only indications for the role of the ICC-ICx-OT pathway in the soundlocalization behavior, but they cannot prove whether or how the space map is used by the motor system for computing head turns in response to auditory stimulation. This could be proven by experiments like the ones presented in this article.

It cannot be excluded that the ICc-Ov-L pathway is also involved in sound localization. It is possible that both pathways work in parallel, the ICC-ICx-OT pathway being the faster one. This would explain why a major effect of the lesions was an increase in response latency. Should this speculation be correct, it can also be concluded that, at least for a few of days after a lesion in the ICc-ICx-OT pathway, the other pathway cannot function "normally," because there were also effects on turning amplitude and the number of correct turns (see also below).

The data also provide insight on how the motor system uses the sensory map. Since the localization deficit was restricted to the regions that had been erased by the lesions from the map, it can be concluded that the turns towards one sound location are mainly triggered by the activity at one locus in the map. Thus, local information in the map constitutes the code for head turning elicited by auditory stimuli. Studies of eye movements elicited by electrical stimulation in the superior colliculus have led to the conclusion that the direction, amplitude, and velocity are based on averaging over the active population of neurons (Lee et al., 1988). Although such a population averaging could not be detected in this study, it cannot be excluded that it takes place locally, that is, within the ranges of bins used for spatial averaging in this study $\left(10-20^{\circ}\right.$ of azimuth).

\section{Possible mechanisms of hehavioral improvement after lesions}

In a recent review, King and Moore (1991) stated that up to now plasticity in auditory space maps of adult individuals has only been observed as a dynamic remapping in the superior colliculus (for a review, see Sparks and Nelson, 1987). The owls used in this study were adults. Thus, this is the first demonstration of neural plasticity after lesions in an auditory space map during adulthood. It should be mentioned, however, that plasticity in the auditory system has been demonstrated for other neural computations, such as frequency tuning (see, e.g., Diamond and Weinberger, 1986; Robertson and Irvine, 1989).

My results are different from the developmental studies of sound localization in the barn owl, in which juvenile, but not adult, owls have been shown to compensate for altered sensory cues induced by plugging one ear (Knudsen et al., 1984a,b). One difference between the earlier studies and the one presented here is that, in the carlicr cxpcriments, peripheral cues were altered, whereas in this study central operations were made. Thus, it might be that the compensatory mechanisms evoked by central injuries are different from, and are effective for a longer time in the life of an animal than, the mechanisms underlying the circuit modifications induced by peripheral manipulations. This may 
especially be true if the lesions are comparatively small such that an innervation of the neurons that lost their input by the lesion is possible by synaptic reorganization or axonal sprouting. Thus, one speculation is that the neural repair occurred within the ICc-ICx-OT pathway by a reorganization of the space map at hierarchically higher centers. A reorganization of the ICcICX-OT pathway would explain that, after the transient phases following the lesions, the response latencies were no longer increased in five of seven cases.

On the other hand, a second hypothesis on the compensatory mechanism is equally probable. It might be that the $\mathrm{ICc}-\mathrm{Ov}-\mathrm{L}$ pathway took over the missing functions of the ICc-ICx-OT pathway. This could have easily occurred within the time course of the improvement of the behavioral reactions, because it would probably not require new connections but only a new weighting of already existing connections. Note that the failure of inducing a behavioral deficit in case M3 is consistent with both hypotheses. If the ICc-Ov-L pathway would have taken over the "normal" functions of the lesioned ICc-ICx-OT pathway, a subsequent lesion in the former pathway should lead to a permanent lesion deficit, similarly as in studies of visually evoked eye movements, in which a lesion deficit was only observed after lesioning both analogous visual pathways (Schiller et al., 1980). It is beyond the scope of the present study to settle all these issues, and clearly more experiments are necessary to do so.

\section{Comparison with sound-localization deficits in mammals}

The most extensive studies on sound-localization deficits induced by lesions are available from studies on mammals, especially hedgehogs, rodents, cats, ferrets, and monkeys (Ravizza and Diamond, 1974; Neff et al., 1975; Thompson and Masterton, 1978; Jenkins and Masterton, 1982; Jenkins and Merzenich, 1984; Kavanagh and Kelly, 1986, 1987; Heffner and Heffner, 1990). While lesions in the pathway analogous to the ICcICx-OT pathway caused sound-localization deficits in rats (Zrull and Coleman, 1991) and hedgehogs (Ravizza and Diamond, 1974), lesions in the inferior colliculus of higher mammals had only minor effects (Masterton et al., 1968; Neff et al., 1975; Thompson and Masterton, 1978). Jenkins and Masterton (1982) report two cases in which lesions of the inferior colliculus caused profound sound-localization deficits. However, in both cases adjacent structures like the brachium of the inferior colliculus or the dorsal nucleus of the lateral lemniscus were also affected, which makes the interpretation of the data difficult. In addition, interpretations of these studies are complicated by the fact that these animals can move their pinnae. Furthermore, only permanent deficits could be investigated in these studies, and a structure with a map comparable to that of the ICx is not known in the inferior colliculus. Thompson and Masterton (1978) investigated reflexive head turning of cats and found influences on the response latency if the lesions were confined to the superior colliculus. This is, in principle, consistent with my findings, especially with the cases $\mathrm{C} 1, \mathrm{M} 1$, and $\mathrm{M} 2$. In most of the studies with cats, the animals could freely walk and a twospeaker paradigm was used (for a review, see Neff et al., 1975). The animals indicated that they could localize the source by walking toward the test speaker. Initially, these experiments failed to demonstrate clear lesion deficits, but after care was taken to ensure open-loop reactions, that is, short sound bursts were used, deficits became obvious. In an improved experimental design, seven instead of two speakers were used, reducing the possibility of tactical learning. Although deficits restricted to a small region within a hemifield were sometimes observed (see Fig. 11 in Jenkins and Masterton, 1982), the authors hesitated to interpret these deficits as indications of a silent area within a hemifield. There is no problem with the interpretation of the data presented here, which show, for sound localization, the first locally well circumscribed lesion deficit within a hemifield. It was therefore concluded that not only is one point of auditory space mapped at one point in the space map, but that also the motor system makes use, though probably not exclusively, of the local information in the space map to compute head turns. This observation was possible, in part, because the auditory nuclei are very large in the owl compared with similarsized animals. This allowed me to destroy parts of the map and demonstrates the advantage of using a specialist for studying sound localization.

\section{References}

Diamond DM, Weinberger NM (1986) Classical conditioning rapidly induces specific changes in frequency receptive fields of single neurons in secondary and ventral ectosylvian auditory cortical fields. Brain Res 372:357-360.

Du Lac S, Knudsen EI (1990) Neural maps of head movement vector and speed in the optic tectum of the barn owl. J Neurophysiol 63: 131-146.

Fujita I, Konishi M (1991) The role of GABAergic inhibition in processing of interaural time difference in the owl's auditory system. J Neurosci 11:722-739.

Heftiner HE, Heffner RS (1990) Effect of bilateral auditory cortex lesions on sound localization in Japanese macaques. J Neurophysiol 64:915-931.

Jenkins WM, Masterton RB (1982) Sound localization: effects of unilateral lesions in central auditory system. J Neurophysiol 47:987-1016.

Jenkins WM, Merzenich MM (1984) Role of cat primary auditory cortex for sound-localization behavior. J Neurophysiol 52:819-847.

Kavanagh GL, Kelly JB (1986) Midline and lateral field sound localization in the albino rat (Rattus norvegicus). Behav Neurosci 100: 200-205.

Kavanagh GL, Kelly JB (1987) Contribution of auditory cortex to sound localization by the ferret (Mustela putorius). J Neurophysiol $57: 1746-1766$.

King AJ, Hutchings ME (1987) Spatial response properties of acoustically responsive neurons in the superior colliculus of the ferret: a map of auditory space. J Neurophysiol 57:596-624.

King AJ, Moore DR (1991) Plasticity of auditory maps in the brain. Trends Neurosci 14:31-37.

King AJ, Palmer AR (1983) Cells responsive to free-ficld auditory stimuli in guinea-pig superior colliculus: distribution and response properties. J Physiol (Lond) 342:361-381.

Knudsen EI (1982) Auditory and visual maps of space in the optic tectum of the owl. J Neurosci 2:1177-1194.

Knudsen EI (1984) Synthesis of a neural map of auditory space in the owl. In: Dynamic aspects of neocortical function (Edelman GM, Gall WE, Cowan WM, eds), pp 375-396. New York: Wiley.

Knudsen EI, Konishi M (1978a) A neural map of auditory space in the owl. Science 200:795-797.

Knudsen EI, Konishi M (1978b) Space and frequency are represented separately in the auditory midbrain of the owl. J Neurophysiol 41: $870-884$.

Knudsen EI, Konishi M (1979) Mechanisms of sound localization in the barn owl (Tyto alba). J Comp Physiol 133:13-21.

Knudsen FI, Konishi M, Pettigrew JD (1977) Receptive fields of auditory neurons in the owl. Science 198:1278-1280.

Knudsen EI, Blasdel GG, Konishi M (1979) Sound localization by the barn owl ( Tyto alba) measured with the search coil technique. J Comp Physiol 133:1-11.

Knudsen EI, Esterly SD, Knudsen PF (1984a) Monaural occlusion alters sound localization during a sensitive period in the barn owl. J Neurosci 4:1001-1011.

Knudsen EI, Knudsen PF, Esterly SD (1984b) A critical period for the recovery of sound localization accuracy following monaural occlusion in the barn owl. J Neurosci 4:1012-1020. 
Knudsen EI, du Lac S, Esterly SD (1987) Computational maps in the brain. Annu Rev Neurosci 10:41-65.

Konishi M, Takahashi TT, Wagner H, Sullivan WE, Carr CE (1988) Neurophysiological and anatomical substrates of sound localization in the owl. In: Auditory function (Edelman GM, Gall WE, Cowan WM, eds), pp 721-745. New York: Wiley.

Lee C, Rohrer WH, Sparks DL (1988) Population coding of saccadic eye movements by neurons in the superior colliculus. Nature 332: 357-360.

Masino T, Knudsen EI (1990) Horizontal and vertical components of head movement are controlled by distinct neural circuits in the barn owl. Nature 345:434-437.

Masterton RB, Jane JA, Diamond IT (1968) Role of brain-stem auditory structures in sound localization. II. Inferior colliculus and its brachium. J Neurophysiol 31:96-108.

Merzenich MM, Jenkins WM, Middlcbrooks JC (1984) Observations and hypotheses on special organizational features of the central auditory nervous system. In: Dynamic aspects of neocortical function (Edelman GM, Gall WE, Cowan WM, eds), pp 397-424. New York: Wiley.

Middlebrooks JC, Knudsen EI (1984) A neural code for auditory space in the cat's superior colliculus. J Neurosci 4:2621-2634.

Moiseff A (1989) Bi-coordinate sound localization by the barn owl. J Comp Physiol 164A:637-644.

Moiseff A, Konishi M (1981) Neuronal and behavioral sensitivity to binaural time difference in the owl. J Neurosci 1:40-48.

Moiseff A, Konishi M (1983) Binaural characteristics of units in the owl's brainstem auditory pathway: precursors of restricted spatial receptive fields. J Neurosci 3:2553-2562.

Neff WD, Diamond IT, Casseday JII (1975) Behavioral studies of auditory discrimination: central nervous system. In: Handbook of sensory physiology, Vol 5/2 (Keidel WD, Neff WD, eds), pp 307-400. Berlin: Springer.

Olsen JF, Knudsen EI, Esterly SD (1989) Neural maps of interaural time and intensity differences in the optic tectum of the barn owl. $J$ Neurosci 9:2591-2605.
Payne, R (1971) Acoustic location of prey by barn owls (Tyto alba). J Exp Biol 54:535-573.

Pollack GD, Wenstrup JJ, Fuzessery ZM (1986) Auditory processing in the mustache bat's inferior colliculus. Trends Neurosci 9:556-561

Ravizza R, Diamond IT (1974) Role of auditory cortex in sound localization: a comparative ablation study of hedgehog and bushbaby. Fed Proc 33:1917-1919.

Robertson D, Irvine DRF (1989) Plasticity of frequency organization in auditory cortex of guinea pigs with partial unilateral deafness. $J$ Comp Neurol 282:456-471.

Schiller PH, True SD, Conway JL (1980) Deficits in eye movements following frontal eye-field and superior colliculus ablations. $J$ Neurophysiol 44:1175-1189.

Sparks DL, Nelson, JS (1987) Sensory and motor maps in the mammalian superior colliculus. Trends Neurosci 10:312-317.

Takahashi TT, Konishi M (1986) Sclcctivity for interaural time difference in the owl's midbrain. J Neurosci 6:3413-3422.

Takahashi TT, Wagner H, Konishi M (1989) Role of commissural projections in the representation of bilateral auditory space in the barn owl's inferior colliculus. J Comp Neurol 281:545-554.

Thompson GC, Masterton RB (1978) Brain stem auditory pathways involved in reflexive head orientation to sound. $J$ Neurophysiol 41: $1183-1202$.

Wagner $\mathrm{H}$ (1991) A temporal window for lateralization of interaural time difference in the barn owl. J Comp Physiol 169A:281-289.

Wagner H, Takahashi T, Konishi M (1987) Representation of interaural time difference in the central nucleus of the barn owl's inferior colliculus. J Neurosci 7:3105-3116.

Withington-Wray DJ, Binns KE, Keating MJ (1990) The developmental cmergence of a map of auditory spacc in the supcrior colliculus of the guinea pig. Dev Brain Res 51:225-236.

Zrull MC, Coleman JR (1991) Detection of a spatial noise stimulus by normals and rats with lesions of the inferior colliculi. In: Abstracts of the Association for Research in Otolaryngology 14th midwinter meeting 1991 (Lim DJ, ed), p 20. St. Petersburg: Association for Research in Otolarygology. 